\title{
Characterization of Nme5-Like Gene/Protein from the Red Alga Chondrus Crispus
}

\author{
Dragutin Perina ${ }^{1,2, *,+}$, Marina Korolija ${ }^{3,4,+}{ }^{+}$Andreja Mikoč ${ }^{1}$, Mirna Halasz ${ }^{1}$, \\ Maja Herak Bosnar ${ }^{3}$ and Helena Ćetković ${ }^{1, *}$ \\ 1 Division of Molecular Biology, Ruđer Bošković Institute, 10000 Zagreb, Croatia; mikoc@irb.hr (A.M.); \\ mimesek@irb.hr (M.H.) \\ 2 Ministry of Health of the Republic of Croatia, 10000 Zagreb, Croatia \\ 3 Division of Molecular Medicine, Ruđer Bošković Institute, 10000 Zagreb, Croatia; mkorolija@mup.hr (M.K.); \\ mherak@irb.hr (M.H.B.) \\ 4 Forensic Science Centre "Ivan Vučetić", 10000 Zagreb, Croatia \\ * Correspondence: Dragutin.Perina@miz.hr (D.P.); cetkovic@irb.hr (H.Ć.); \\ Tel.: +385-1469-8453 (D.P.); +385-1456-1115 (H.Ć.) \\ + These authors contributed equally to this work.
}

Received: 28 November 2019; Accepted: 19 December 2019; Published: 21 December 2019

\begin{abstract}
The Nme gene/protein family of nucleoside diphosphate kinases (NDPK) was originally named after its member Nm23-H1/Nme1, the first identified metastasis suppressor. Human Nme proteins are divided in two groups. They all possess nucleoside diphosphate kinase domain (NDK). Group I (Nme1-Nme4) display a single type NDK domain, whereas Group II (Nme5-Nme9) display a single or several different NDK domains, associated or not associated with extra-domains. Data strongly suggest that, unlike Group I, none of the members of Group II display measurable NDPK activity, although some of them autophosphorylate. The multimeric form is required for the NDPK activity. Group I proteins are known to multimerize, while there are no data on the multimerization of Group II proteins. The Group II ancestral type protein was shown to be conserved in several species from three eukaryotic supergroups. Here, we analysed the Nme protein from an early branching eukaryotic lineage, the red alga Chondrus crispus. We show that the ancestral type protein, unlike its human homologue, was fully functional multimeric NDPK with high affinity to various types of DNA and dispersed localization throughout the eukaryotic cell. Its overexpression inhibits both cell proliferation and the anchorage-independent growth of cells in soft agar but fails to deregulate cell apoptosis. We conclude that the ancestral gene has changed during eukaryotic evolution, possibly in correlation with the protein function.
\end{abstract}

Keywords: Nme gene/protein family; Nme5; red alga; Chondrus crispus; eukaryotic evolution; Nme evolution

\section{Introduction}

The Nme/Nm23/NDPK is a gene/protein family of nucleoside diphosphate kinases (NDPK), enzymes that transfer the terminal phosphate group from (d)NTP (mainly ATP) to any (d)NDP to produce (d)NTPs. In the late eighties it was discovered that one of the family members, Nm23-H1/Nme1/NDPK A, suppresses metastasis formation and was, therefore, identified as the first metastasis suppressor gene/protein [1]. To date, ten different Nme genes have been identified in humans. Nme1 and Nme2 are the most studied representatives due to their involvement in cancer progression and metastasis. Nme proteins have been divided into two groups based on their phylogenetic characteristics, presence of protein domains and exon/intron structure [2]. Group I and 
Group II constitute human Nme1-Nme4 and Nme5-Nme9 proteins, respectively. All Nme enzymes possess at least one nucleoside diphosphate kinase (NDK) domain. There is a single histidine residue involved in the catalytic mechanism, conserved in all known active NDPK enzymes. Active NDK domain acts via a ping-pong mechanism, in which the phosphorylation of the histidine residue occurs by transfer of the terminal phosphate group from (d)NTP. These phosphoenzymes can than transfer the phosphate group to any (d)NDP to produce (d)NTP. Group I proteins display a single type NDK domain, whereas Group II proteins display a single or several NDK domains of different types, sometimes accompanied by extra-domains. The Nme10 protein has passed through a separate evolutionary history since it seems evident that its NDK domain was inserted relatively recently and, therefore, cannot be classified in either of the two groups [2]. Interestingly, it seems that the basic function of NDPKs to form NTPs and dNTPs is only inherent to Group I members [3]. To date none of the tested Group II Nme family members were able to transfer terminal phosphate group from (d)NTP to (d)NDP, with a potential exception of Nme6 [4]. At least one of the representatives of Group I proteins is present in all three domains of life. In eukaryotes, members of the Group I proteins are enzymatically active in their hexameric form. The Group I proteins show different cellular localization. Nme1/Nme2 are localized in the cytosol and in the nucleus, Nme4 is exclusively mitochondrial, while Nme3 is considered to be both cytoplasmic and mitochondrial [5]. Interestingly, the Nme genes/proteins have several additional biochemical roles. It has been suggested that they may function as transcription regulators [6], protein kinases [7], and DNases [8]. They also possess diverse biological roles in the cell, including proliferation [9,10], development [11,12], differentiation [13,14], ciliary functions [15], endocytosis and membrane remodeling [16,17], actin-based cellular remodeling [18], apoptosis [8], cell-cell communication [19], and cell adhesion [20,21]. In spite of extensive scientific research in this field for more than two decades, the mechanisms by which the members of the Nme protein family execute their biological functions are still not elucidated.

In contrast to Group I members, the accumulating data suggest that none of the Group II members display measurable NDPK activities [3,22-24], even though some of them are able to autophosphorylate [3,23]. The multimeric forms of Group II members have not yet been determined. Some features like the three amino acid insertion in the Kpn-loop (named after the "Killer of prune" mutation of the Drosophila Awd NDP kinase) present in all human Group II members, indicate the lack of stability of the multimeric structure potentially resulting in defective catalytic activity [24]. Although little is known about the Group II members' biology it seems that they might have highly divergent functions. Nme5 has been found to be most prominently expressed in human testes. It localizes within axonemal microtubules of spermatid and spermatozoan flagella, suggesting its involvement in sperm motility $[24,25]$. Nme5 was found to be strictly associated with active spermatogenesis in both mouse and lizard [26]. Additionally, expression of Nme5 in mice increased the cellular levels of GPX-5 (glutathione peroxidase-5), which suggests its critical role in eliminating reactive oxygen species during spermatogenesis [27].

Comprehensive proteomic analysis of isolated human ciliary axonemes revealed that Nme5 is also present in somatic airway epithelia cells, together with Nme7 and Nme9 [28]. Furthermore, Nme5 has been identified as a contributor of innate resistance to gemcitabine [29,30]. It has, also, been shown that simvastatin treatment of human prostate cancer cell line (PC3) resulted in reduced protein levels of Nme5 [31]. Expression analyses of 23 purine metabolism genes in Alzheimer's showed deregulation at the mRNA level of 10 genes, including Nme1, Nme3, Nme5, Nme7, and adenylate kinase 5 (AK5 [32]).

Vertebrate Nme5 possesses a C-terminal Dpy-30 domain of generally unknown function. In Chlamydomonas reinhardtii, this domain and its flanking sequence mediate the assembly and modulation of flagellar radial spoke complexes [33]. In Caenorhabditis elegans the DPY-30 protein is essential for dosage compensation in early embryogenesis, while in males $(\mathrm{X} 0)$ it is required for developmental processes such as coordinated movement, normal body size, correct tail morphology and mating behavior [34]. In mammals, this Dpy-30 is involved in the histone H3K4 methylation and cell fate specification of embryonic stem cells [35]. 
The human Nme6 was reported independently by two groups in 1999 [36]. Compared to Nme1 and Nme2, Nme6 has additional residues on the $\mathrm{N}$ and $\mathrm{C}$ termini and an insertion in the Kpn-loop. The fusion protein with a GST tag showed some kinase activity, although lower compared to human Nme1 or Nme2 [4]. Our results on Nme6-like protein in sponges suggest that the function of Nme6 gene has probably changed during metazoan evolution in correlation with the structure of the protein [22]. Recent analyses of melanoma driver genes revealed that Nme6 has a significant enrichment of somatic mutations rate [37]. Further, it has been shown that both Nme6 and Nme7 are important in embryonic stem cell renewal [38].

The most intriguing result considering Group II members came up upon the discovery that recombinant human Nme7 induces a stable, naïve-like state in human embryonic stem cells and induces pluripotent stem cells [39]. $\mathrm{Nme}^{-/-}$mice developed situs inversus and hydrocephalus, which indicates a role of Nme7 in biogenesis or a function in motile cilia [40]. Normal male fertility and the absence of rhinitis/sinusitis observed in $\mathrm{Nme7}^{-/-}$mice indicates the importance of Nme7 in biogenesis of ependymal or embryonic node cilia, rather than the role in respiratory epithelium and spermatozoa cilia/flagella [40]. In vitro co-sedimentation assays using recombinant proteins showed that both mouse and Chlamydomonas Nme7 directly bind to microtubules [41], suggesting its ancient function that might be universal for all eukaryotes. Human Nme7 contains a DM10 domain of unknown function followed by two NDK domains of which only the first one is able to autophosphorylate [23]. An identical fluorescence pattern of both DM10 alone and the full length Nme7 (TcNDPK2) GFP-fused products were detected linked to the cytoskeleton and flagellum of Trypanosoma cruzi, which gives the first insight into the role of the DM10 domains in Nme enzymes [42].

Human Nme8 is an ortholog of the sea urchin IC1 that encodes a component of sperm outer dynein arms, and is implicated in primary ciliary dyskinesia, left-right asymmetry randomization, and male infertility [43].

Nme9 gene displays a similar exon/intron structure as Nme8, and therefore it seems likely that Nme9 originates from an incompletely translocated duplication of Nme8 [2]. Both proteins possess thioredoxin domain at the N-terminus. Nme8 is distributed in human sperm [44], where it is probably required during the final stages of sperm tail maturation [45]. On the other hand, Nme9 is a microtubule-binding protein expressed predominantly in the cilia of lung airway epithelium and spermatid manchette and axoneme [46]. Recently, the association between Nme8 locus polymorphism and Alzheimer's disease has been demonstrated $[47,48]$.

Our comprehensive analyses of the Nme family in eukaryotes revealed conservancy of the Group II ancestral type proteins in several species from three eukaryotic supergroups. We analyzed Nme proteins from early branching eukaryotic lineage. The red algae (Rhodophyta) are one of the oldest groups of eukaryotic algae formed during the primary endosymbiosis event which enabled the emergence of the first photosynthetic eukaryote [49]. The red macroalgal fossil, 1.2 billion years old, provides the oldest evidence of a multicellular, sexually reproducing eukaryote [50]. The genome of Chondrus crispus, Irish moss, has been sequenced, which was a prerequisite for the positioning of red algae as excellent model organisms for understanding Nme evolution [51]. Our analyses revealed that the ancestral type of Nme5-like protein, in contrast to the human homologue, was a fully functional multimeric NDP kinase. This three-domain protein shows high affinity to various types of DNA and displays a dispersed localization throughout the eukaryotic cell. Simple bioassays revealed that cells overexpressing this enzyme exhibit inhibition of proliferation and anchorage independent growth in soft agar but show no influence on apoptosis. We concluded that the structure of the ancestral gene has changed significantly during eukaryotic evolution in correlation with the protein function. 


\section{Results}

\subsection{Nme Family in Eukaryotes}

The increasing number of sequenced eukaryotic genomes reveals that the Nme superfamily distribution is wider than previously documented. We analyzed the distribution of Nme proteins in all six major eukaryotic supergroups: Opisthokonta, Amoebozoa, Plantae, Excavata, Chromalveolata, and Rhizaria. We found Nme homologues from both Group I and Group II in the representatives of all major eukaryotic supergroups (Table 1). Broader analyses of Nme enzymes, revealed that 1448 Nme proteins are present in 398 eukaryotic species across all six eukaryotic supergroups. In all these species, 37 types of Nme enzymes were found. The majority of these proteins possess the same combination of domains present in the human Nme homologues, but there are also many additional distinct domains, suggesting novel connections between the Nme family and different cellular processes.

In representatives from all eukaryotic supergroups analyzed, more than one Group I Nme gene was found. It was previously proposed that duplications of Group I Nme genes occurred independently and frequently in metazoan evolution. However, the evolutionary relations were generally not well resolved [2,53-55]. As in our earlier studies, phylogenetic analyses of Group I members (data not shown) do not produce a well-supported tree, and therefore we can only speculate on evolutionary relations between duplicated Nme Group I genes present in distant eukaryotic supergroups. Recent human Nme1-4 genes group together, and are generated by duplication events that occurred in the vertebrate lineage [2,53]. On the contrary, Group II members seem to have emerged earlier in the eukaryotic evolution. It has been proposed that Nme5, Nme6, and Nme7 were most likely present in the eukaryote ancestor [55]. Our phylogenetic analyses, however, show that Nme6 probably arose in the Unikonts lineage (Figure 1A). Nme6-like gene is present in Apusozoa representative who is presumably the closest relative of Opisthokonts, and in Amoeboza representatives (Table 1). Nme6-like gene seemingly arose by the duplication of Nme5-like in the ancestor of Unikonts, probably before the separation of Amoebozoa (Figure 1A). It was proposed that -Nme8 is a choanoflagellate/metazoan innovation [55]. We found Nme8-like genes also in Fungi (Table 1). Nme8-like appeared earlier in Unikont evolution than previously suggested, probably in the ancestor of all Opisthokonts, after the separation of Apusozoa. Nme5-like and Nme7-like seem to be widely distributed throughout eukaryotic supergroups which indicates that the ancestor of all eukaryotes probably had both genes. The only exception is the secondary loss within Amoebozoa lineage, a supergroup without any sequenced representative, containing neither Nme5-like nor Nme7-like. In the majority of eukaryotes analyzed Nme7-like protein possesses the same domain structure as its human homologue, which indicates that the eukaryotic ancestor probably possessed Nme7-like gene with an identical domain organization structure. On the contrary, the distribution of Nme5-like revealed that the eukaryotic ancestor probably possessed a Nme5-like domain organization dissimilar to the human homologue. Basal representatives from three eukaryotic supergroups also possess an adenylate kinase (ADK) domain present at the C-terminal end of Nme5-like (Table 1). Adenylate kinases are phosphotransferase enzymes present in all three domains of life and they are a part of the cellular machinery responsible for nucleotide synthesis. So far, nine different adenylate kinase isoenzymes have been identified and characterized in human. Nme5-like from red algae C. crispus (Nme5-likeCc) possesses an ADK domain that groups together with human AK1/AK5 (Figure 1B). It is comprised of well conserved elements essential for the phosphotransferase activity: the glycine rich region (P-loop), (d)NMP binding site, and LID domain, which is responsible for the substrate ((d)NTP or (d)NDP) binding (Figure 1C). 
Table 1. Schematic architecture of Nme proteins present in eukaryotic representatives. Numbers indicate amino acids. Proteins are represented in a scale 1:10 (1 mm = 10 amino acids). Protein domains have been indicated with colored boxes and each protein has been searched against SMART (Simple Modular Architecture Research Tool)/Pfam databases. Abbreviations of domain names are retrieved from SMART/Pfam databases and indicated in the figure. Shortened names include: NDK, nucleoside diphosphate kinase; ADK, adenylate kinase; Dpy-30, domain found in the Dpy-30 proteins; DM10, uncharacterized domain; IQ, calmodulin-binding motif; $\mathrm{TM}$, transmembrane region; Domain which is not retrieved from SMART/Pfam database: MLS, mitochondrial localization signal according to [52].

\begin{tabular}{|c|c|c|c|c|}
\hline & \multirow{2}{*}{$\begin{array}{l}\text { Eukaryotic } \\
\text { Supergroup }\end{array}$} & \multirow{2}{*}{ Organism } & \multicolumn{2}{|c|}{ Nme Schematic Domain Presentation } \\
\hline & & & Group I & Group II \\
\hline \multirow{4}{*}{ Unikonts } & \multirow[t]{2}{*}{ Opistokonts } & Homo sapiens & 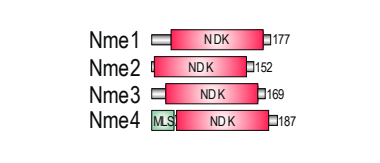 & 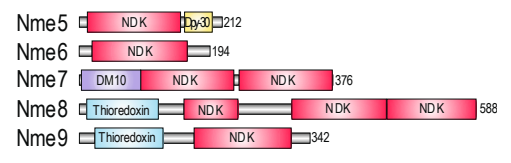 \\
\hline & & Spizellomyces punctatus & $\begin{array}{lll}\text { NmeGp1SpA NoK } & \text { No } \\
\text { NmeGp1SpB } & \text { NOK } \\
1185\end{array}$ & 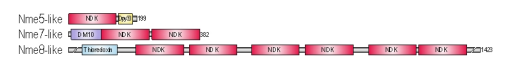 \\
\hline & Apusozoa & Thecamonas trahens & 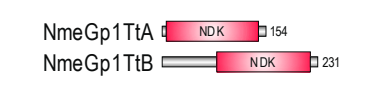 & 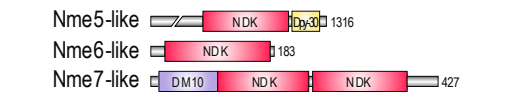 \\
\hline & Amoebozoa & Dictyostelium purpureum & $\begin{array}{l}\text { NmeGp1DpA NOK } 1152 \\
\text { NmeGp1DpB }\end{array}$ & Nme6-like ${ }_{\text {NoK }}^{153}$ \\
\hline \multirow{5}{*}{ Bikonts } & Rhizaria & Bigelowiella natans & 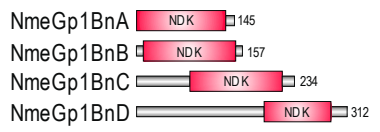 & 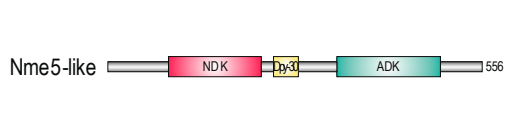 \\
\hline & Chromalveolata & Phytophthora sojae & 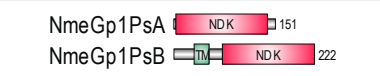 & 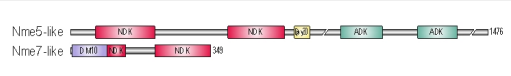 \\
\hline & \multirow{2}{*}{ Plants } & Volvox carteri & $\begin{array}{l}\text { NmeGp1VcA }{ }_{\text {NOK }}^{150} \\
\text { NmeGp1VCB }{ }_{\text {NOK }}^{190}\end{array}$ & 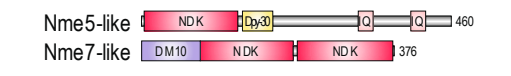 \\
\hline & & Chondrus crispus & $\begin{array}{lll}\text { NmeGp1CCA } & \text { NOK } \\
\text { NmeGp1CCB } & \text { NOK } \\
\text { NmeGp1CcC } & \text { NoK } \\
\text { NoK }\end{array}$ & Nme5-like 4 NoK \\
\hline & Excavata & Naegleria gruberi & $\begin{array}{lll}\text { NmeGp1NgA } & \text { NoK } \\
\text { NmeGp1NgB } & \text { NoK } \\
151\end{array}$ & 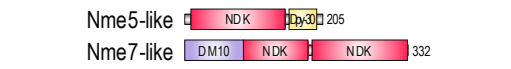 \\
\hline \multicolumn{3}{|c|}{ Eukaryotic ancestor } & 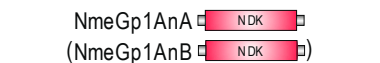 & 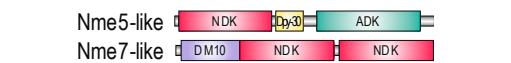 \\
\hline
\end{tabular}



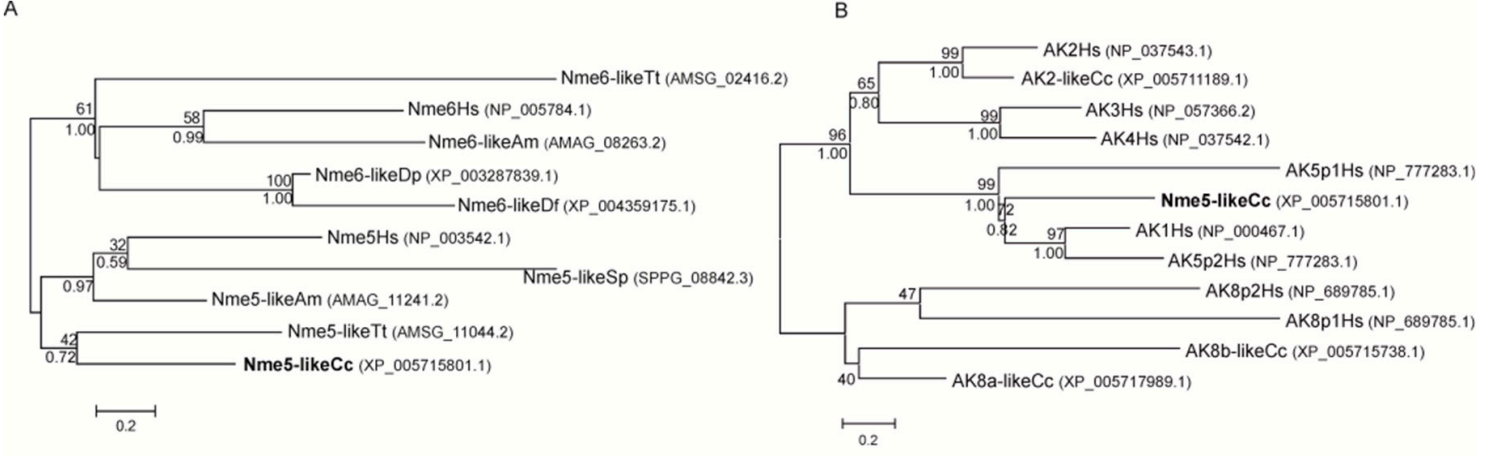

D
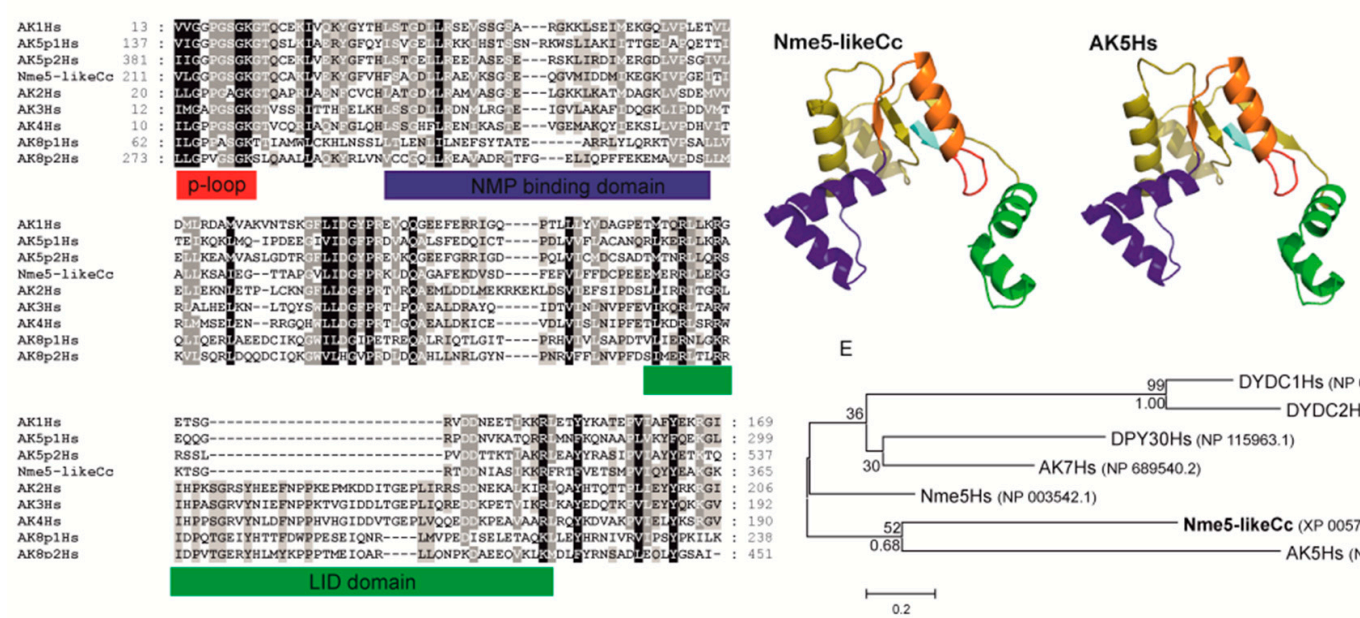

E

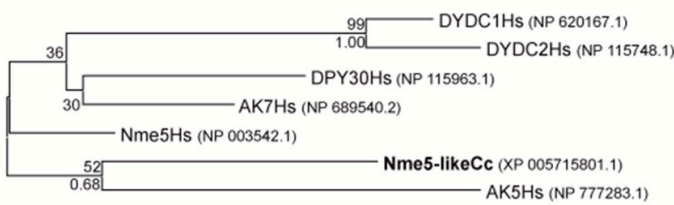

F
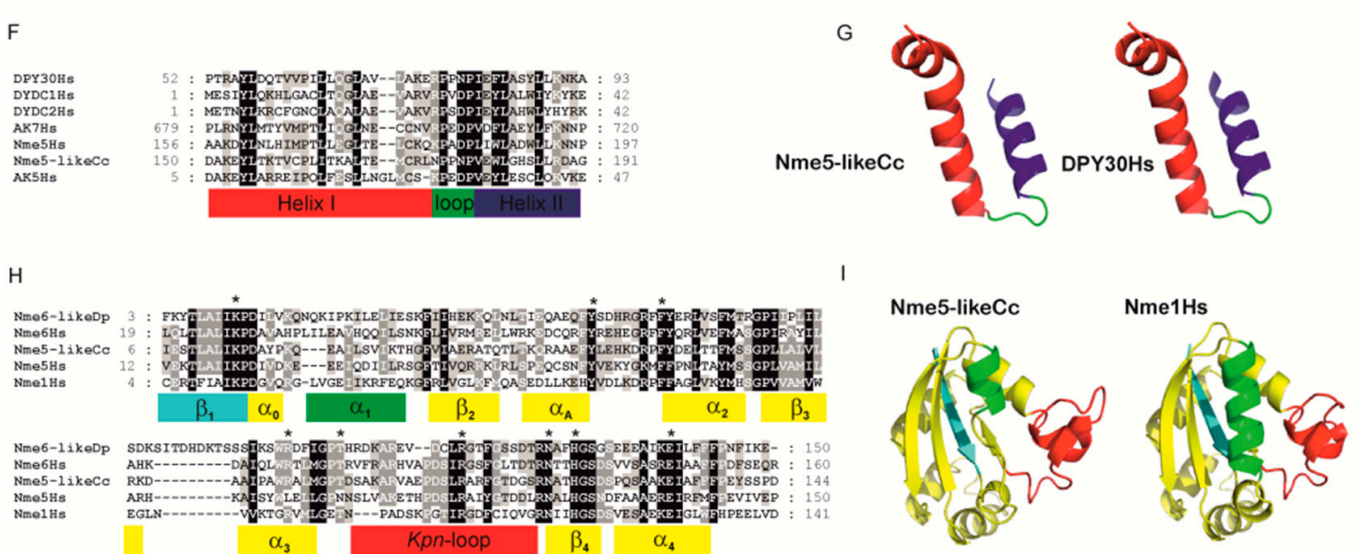

Figure 1. Maximum likelihood phylogenetic trees illustrating relationship between NDK (A), ADK (B) and Dpy-30 (E) domains from Nme5-likeCc and protein domains from selected representatives. MCMC (Markov chain Monte Carlo) values are given below lines, bootstrap values above and accession numbers are given after protein names and species abbreviation. The scale bar indicates genetic distance of the branch lengths. Amino acid sequence alignments of ADK (C), Dpy-30 (F), and NDK (H) domains from representative species are accompanied with colored bars which show major motifs in these domains. Nine amino acid residues important for quaternary structure, nucleotide binding and catalysis are marked with asterisk. Homology modeling of the ADK (D), Dpy-30 (G), and NDK (I) sequences from Nme5-likeCc against the crystallographic algorithms of the human AK5 (PDBID: 2BWJ), DPY30 (PDBID: 3G36) and Nme1 (PDBID: 3L7U), respectively. Shortened species names include Hs, Homo sapiens; Cc, Chondrus crispus; Tt, Thecamonas trahens; Dp, Dictyostelium purpureum; Am, Allomyces macrogynus; Df, Dictyostelium fasciculatum; Sp, Spizellomyces punctatus. 
Homology modeling of the ADK sequence from Nme5-likeCc against the crystallographic algorithms of the human AK5 (Protein Data Bank ID 2BWJ) demonstrated similar monomeric structures (Figure 1D). Human AK5 possesses Dpy-30 domain at the N-terminus, which may indicate that recent human AK1/AK5 clade arose when ancestral three-domain Nme5-like split into Nme5 and AK5. Phylogenetic analyses of the Dpy-30 domain support this thesis as Nme5-likeCc groups with human AK5, rather than with any other human Dpy-30 protein (Figure 1E). Dpy-30 domain seems to be well conserved, with hydrophobic residues and prolines present in all analyzed enzymes from human and red algae (Figure 1F). The modeled Dpy-30 domain from the Nme5-likeCc is comprised of a helix-loop-helix structure identical to the human Dpy-30 domain (Figure 1G). The two amino acid deletion observed in the human Nme5 and the Nme5-likeCc sequence located in the $\alpha 1$ helix and three amino acid insertion in the Kpn-loop (Figure $1 \mathrm{H}$ ) cause significant structural changes in monomer NDK structure, compared to Nme1 which may prevent hexamer assembly and/or enzymatic activity (Figure 1I). However, the ATP binding cavity in the hexameric structure of Nme5-likeCc seems to be much more conserved than it is the case in human Nme5 (Supplementary File Figure S1). Although, NDPK domains are not significantly conserved (Supplementary File Table S1), Nme5-likeCc possesses the NDK domain with all nine residues essential for ATP-binding, quaternary structure and catalysis, unlike the inactive human Nme5 homologue. Therefore, we produced recombinant Nme5-likeCc to test its activity.

\subsection{The Ancestral Nme5-LikeCc Protein Forms a Multimer}

Approximately $10 \mu \mathrm{g}$ of soluble recombinant Nme5-likeCc protein was obtained from $1 \mathrm{~L}$ of bacterial culture (Figure 2A). Most of the protein was insoluble and ended up in the pellet fraction. The multimeric structure is required for the NDPK activity $[14,56,57]$. Eukaryotic Nme enzymes that belong to Group I form trimers of parallel dimers forming an active hexamer. Dissociated subunits of these Nme enzymes do not possess NDPK activity, although every monomer possesses one catalytic site [14]. Multimeric structure of any Group II Nme member is not yet determined or not even predicted, although it is speculated that the trimeric association might be greatly altered in human Nme5, and it is strongly in favor of a dimeric structure [24]. A high-molecular ( $>250 \mathrm{kDa})$ oligomeric structure was found after cross-linking the Nme5-likeCc protein with glutaraldehyde. Previously described human Nme1 was used as control (Figure 2B). The multimeric structure of Nme5-likeCc was also confirmed by gel filtration (Figure 2C).

\subsection{Recombinant Nme5-LikeCc Possesses NDPK Activity and Binds Nonspecifically to Various Types of DNA}

The kinase activity of the recombinant Nme5-likeCc was quantified using a PK-LDH coupled method that detects (d)ADP/(d)GDP as product of the phosphotransfer reaction between $(\mathrm{d}) \mathrm{ATP} /(\mathrm{d}) \mathrm{GTP}$ and dTDP nucleotides. The specific kinase activities of the Nme5-likeCc enzyme were measured and found to be $273 \pm 36 \mathrm{U} / \mathrm{mg}$, $184 \pm 14 \mathrm{U} / \mathrm{mg}$ and $225 \pm 24 \mathrm{U} / \mathrm{mg}$, when ATP, dATP and GTP were used as phosphate donors, respectively. In comparison, the NDP kinase activity of Nme proteins ranged from $208 \mathrm{U} / \mathrm{mg}$ to $2700 \mathrm{U} / \mathrm{mg}$ [58]. The specific activities of the Nme5-likeCc kinase were similar and within the previously reported range for the human Nme1/2 protein. This protein is the first Group II Nme family member with similar NDPK activity as the Group I Nme proteins. Interestingly, purified recombinant Nme5-likeCc is devoid of detectable NDP kinase activity when dGTP was used as the phosphate donor.

Nme proteins are able to bind nonspecifically and sequence-specific single-stranded linear/circular DNA and/or double stranded DNA. For example, Nme2 is involved in DNA structural changes necessary for the activity of the $c-m y c$ promoter [59]. To test binding activities, Nme5-likeCc protein was incubated with various types of DNA; single-stranded circular DNA from the bacteriophage $\varphi$ X174, double-stranded circular DNA (bacteriophage $\varphi$ X174 RF I), double-stranded 57-bp nuclease hypersensitive element of the $c-m y c$ promoter and single-stranded telomeric DNA (TTAGGG)6. The 
recombinant protein displayed the ability to bind to all tested DNA types, showing the DNA band retardation effect (Figure 3).

A

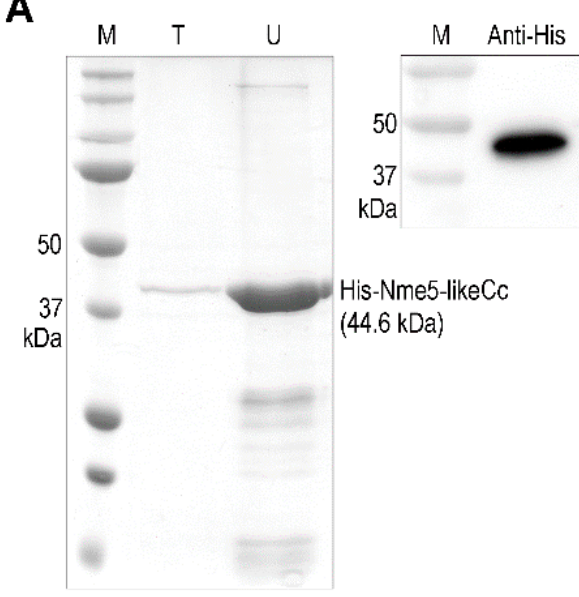

\section{B}

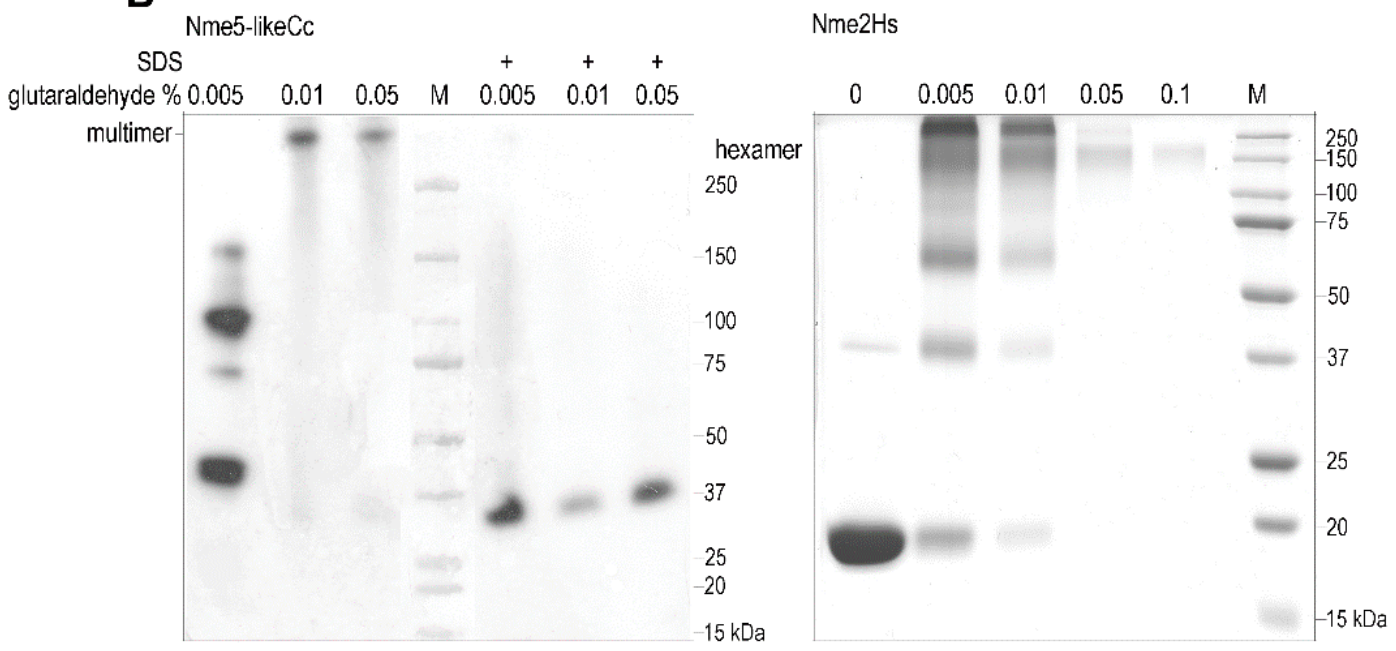

C

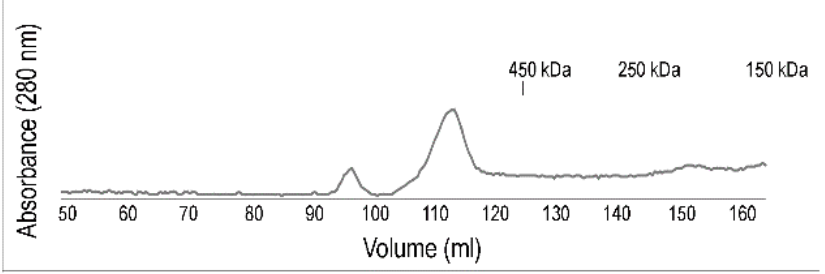

Figure 2. Purification and oligomerization of Nme5-likeCc protein. (A) Recombinant His-Nme5-likeCc, purified with cobalt-charged agarose column-TALON (T), concentrated and desalted using Ultracel (U) was blotted against anti-His antibody (1:5000) and visualized using chemiluminescence detection. (B) Cross-linking of Nme5-likeCc protein. Purified recombinant protein Nme5-likeCc (300 ng) was pre-incubated in PBS at room temperature with glutaraldehyde to initiate the cross-linking. After quenching, the reaction product was subjected to $12 \%$ SDS-PAGE, transfer on PVDF Hybond-P membrane, incubated with anti-His antibody (1:5000) and visualized using chemiluminescence detection. Human Nme2 protein (Nme2Hs) was used as control. (C) Size exclusion chromatography. Recombinant Nme5-likeCc was loaded onto HiLoad 26/600 Superdex 200 prep grade column and eluted with Nme buffer at a flow rate of $1 \mathrm{~mL} / \mathrm{min}$. The standard protein markers for the gel filtration chromatography were as follows: ferritin $(440 \mathrm{kDa}), \beta$-amylase $(200 \mathrm{kD})$ and alcohol dehydrogenase $(150 \mathrm{kD})$. 


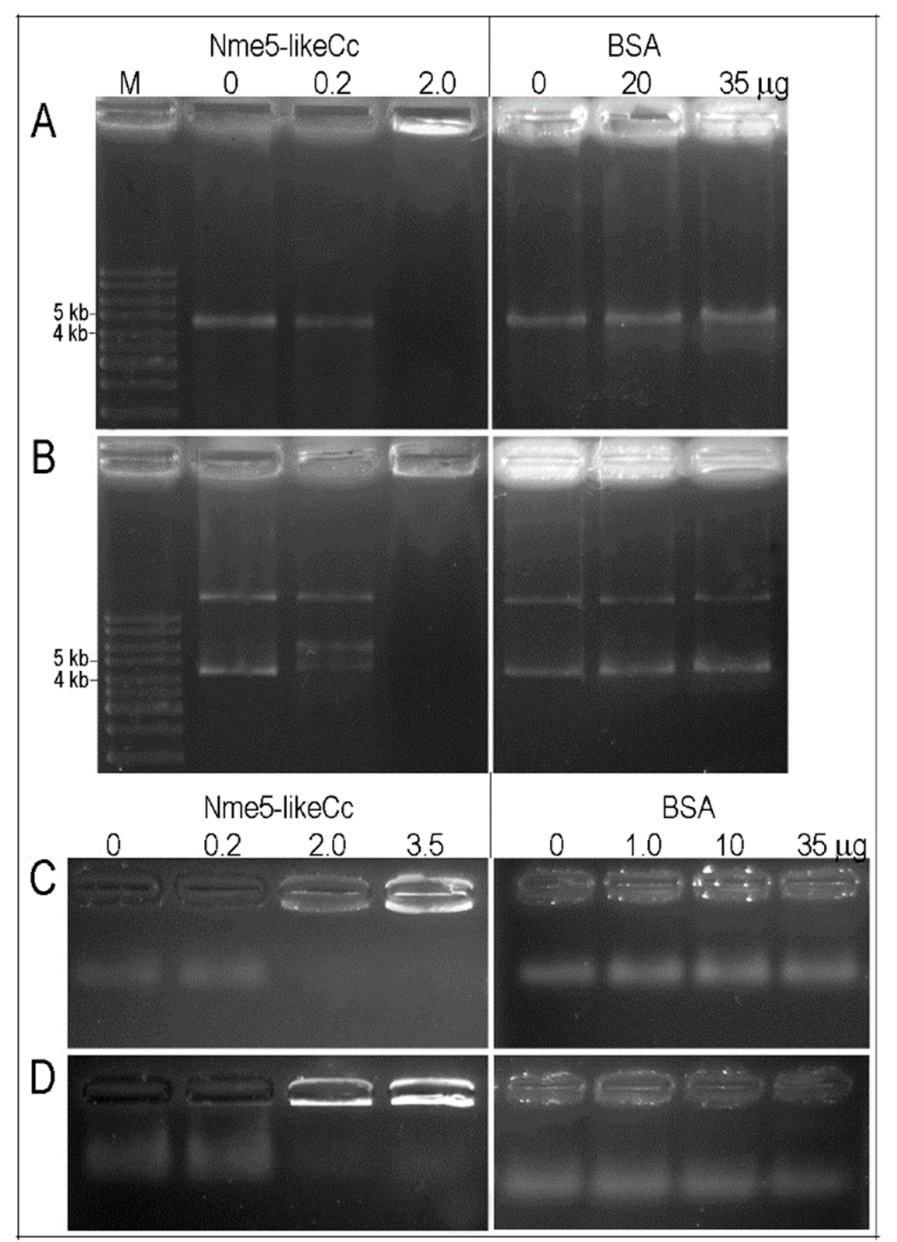

Figure 3. DNA-binding activity of the Nme5-likeCc protein. The reaction was performed in buffer containing $100 \mathrm{mM} \mathrm{KCl}, 10 \mathrm{mM} \mathrm{MgCl} 2,50 \mathrm{mM}$ Tris $\mathrm{HCl} \mathrm{pH}$ 7.5, $0.2 \mathrm{mM} \mathrm{DTT}, 10 \mu \mathrm{g} / \mathrm{mL}$ BSA and (A) $10 \mathrm{ng}$ of single-stranded circular DNA or (B) $10 \mathrm{ng}$ of double-stranded circular DNA or (C) $30 \mathrm{ng}$ of single-stranded 36-bp DNA or (D) 30 ng of double-stranded 57-bp DNA and purified Nme5-likeCc protein as indicated. BSA was used as control. Products were analyzed in $1 \%$ agarose gel $(\mathbf{A}, \mathbf{B})$ or $4 \%$ agarose gel $(\mathbf{C}, \mathbf{D})$ and stained with SYBR gold. Notice that protein-DNA complex remain trapped in the wells at 2 and $3.5 \mu \mathrm{g}$ protein amounts.

\subsection{The Ancestral Nme5-LikeCc Protein Localizes in Nucleus and Cytoplasm}

Nme enzymes are mainly cytoplasmic, but can be found, at least transiently, associated with membranous structures and in the nuclei [15]. Several of them (Nme3, Nme4 and Nme6) localize in mitochondria, at least partly. Nme4 possesses the canonical mitochondrial signaling sequence and exclusively localizes in this organelle [52,60]. Human Nme7 was recently identified as a centrosomal protein [23], while Nme5 was found to be microtubule associated [25]. We transiently transfected HeLa and HEK293T cells with GFP-Nme5-likeCc and analyzed the cells $48 \mathrm{~h}$ post transfection using confocal laser scanning microscopy (Figure 4). Since ancestral Nme5-likeCc seems to have characteristics of an active Nme enzyme, unlike the recent human homologue Nme5, we investigated its localization in comparison to other active NME members, namely Nme1. Human Nme1 is mainly localized in the cytoplasm and to a lesser extent in the nucleus of HEK293T, which is consistent with a previous study [61]. Protein GFP-Nme5-likeCc is dispersed throughout the cytoplasm rather than associated with a specific organelle. The overlay (yellow signal) indicates colocalization of the human Nme1 and Nme5-likeCc in the cytoplasm. A more pronounced nuclear localization for the GFP-Nme5-likeCc in HEK293T cells can be seen very clearly (Figure 4). 


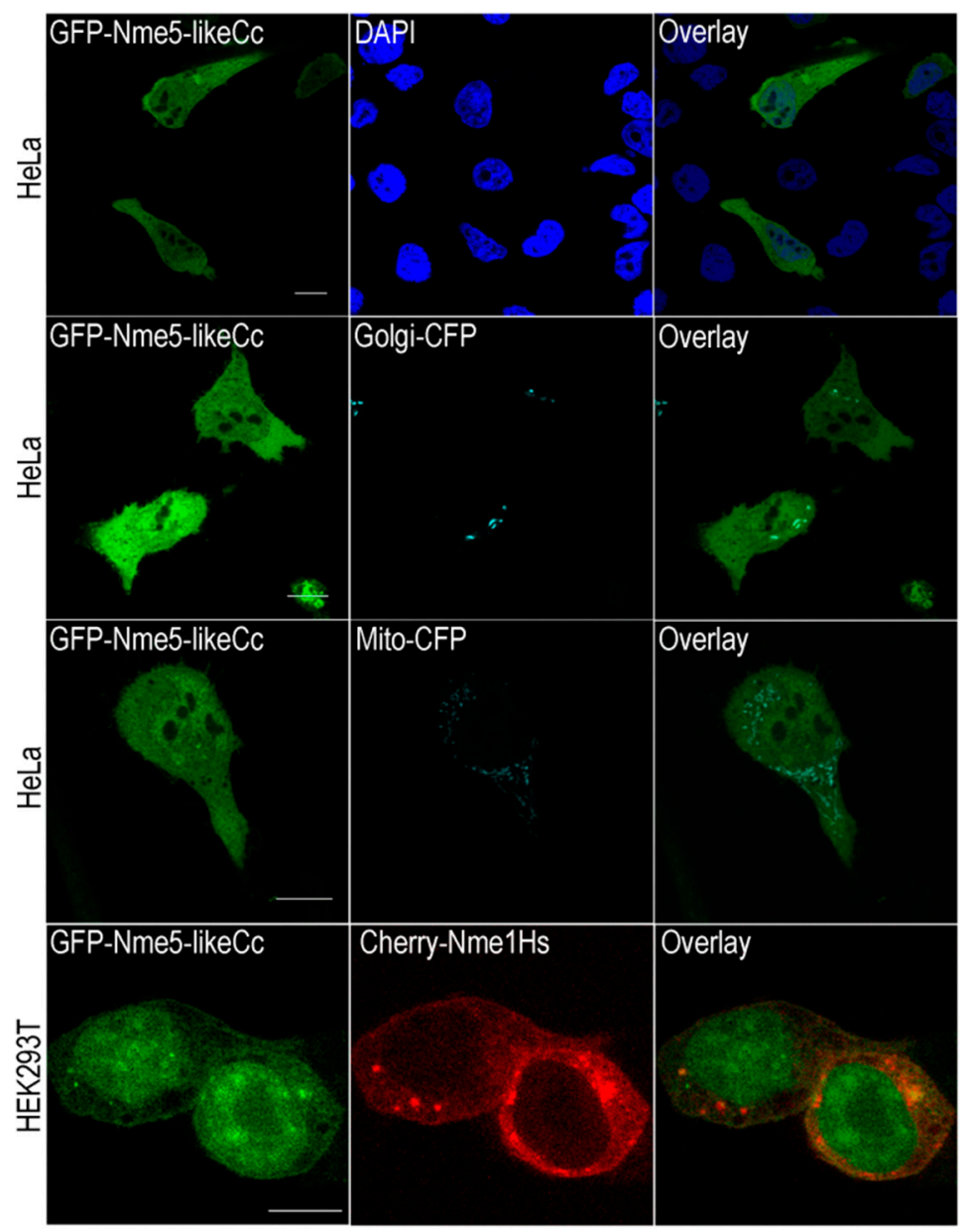

Figure 4. Subcellular localization of Nme5-likeCc. HeLa and HEK293T cells were transiently transfected with pEGFP-Nme5-likeCc (green fluorescence), pCherry-Nme1Hs (red fluorescence), pECFP-Golgi (cyan) and pECFP-mitochondria (cyan). The overlay (yellow) indicates colocalization of the human Nme1 and Nme5-likeCc. Scale bar $=10 \mu \mathrm{m}$.

\subsection{The Ancestral Nme5-LikeCc Protein Diminished Colony Growth in HEK293T Cell Line and Inhibited Cell Proliferation}

It has been demonstrated that the human Nme1 suppresses anchorage independent growth in soft agar in human breast adenocarcinoma cell lines MDA-MB-435 and MDA-MB-231. Moreover, Nme2, Nme4 and Nme5 significantly diminished colony growth in both cell lines [61]. Another study showed that stably-transfected chronic myeloid leukemia K562 cells, expressing RNAi for post-transcriptional silencing of $\mathrm{Nme1}$ gene, exhibited a markedly increased ability to form colonies in terms of number and size compared to the control [62]. Furthermore, it has been established that the murine neuroblastoma cell line N1E-115 expressing Nme3 formed significantly fewer colonies in soft agar [63], while both Nme2-expressing NIH3T3 fibroblasts and Nme2-expressing HLK3 hepatocytes form colonies, unlike control cells that do not form any [64]. Compared to control, stable transfectants of human neuroblastoma NB69 cell lines expressing Nme1 and mutant Nme1S120G form 2.8 and 3.6 times more colonies on soft agar, respectively, indicating that Nme1 aberrations provide neuroblastoma cells with additional in vitro colonization ability [65]. Since Nme family members seem to have an impact on soft agar colony forming in various cell types, we tested Nme5-likeCc prospective suppression. In comparison to control cells, the transfected HEK293T cells exhibited decreased ability to form colonies on soft agar by 1.8-fold $\left(p=2.69 \times 10^{-6}\right)$ (Figure $\left.5 \mathrm{~A}\right)$. The colonies formed by the Nme5-likeCc HEK293T cells were significantly smaller, (the largest were composed of 25 cells) compared to the colonies formed by the control empty vector (mostly $>40$ cells). Colonies with more than 20 cells were 
counted. Further, we analyzed the effect of Nme5-likeCc on cell proliferation. The growth rate of cells was evaluated at different time points after transfection, to determine whether the overexpression of Nme5-likeCc affects cell proliferation (Figure 5B). The pcDNA3 "empty" vector was used as control. The transfection markedly increased Flag-Nme5-likeCc levels (Figure 5C). Subsequently, the proliferation of pcDNA3-Nme5-likeCc-transfected HEK293T cells decreased 1.83-fold $(p=0.0004)$ comparing to cells with pcDNA3 control (Figure 5B). The cell viability decreased by $45.4 \% 72 \mathrm{~h}$ post-transfection compared to cells possessing the control vector. The results presented in Figure $5 \mathrm{~B}$ demonstrate that while the Nme5-likeCc inhibits proliferation of HEK293T cells tested at $48 \mathrm{~h}$ and $72 \mathrm{~h}$ post-treatment, it enhances cell proliferation 1.46-fold ( $p=0.005$ ) when compared to cells with pcDNA3 control $24 \mathrm{~h}$ post-transfection. The results of these assays show that the Nme5-likeCc modulates cell proliferation in the HEK293T cell line.
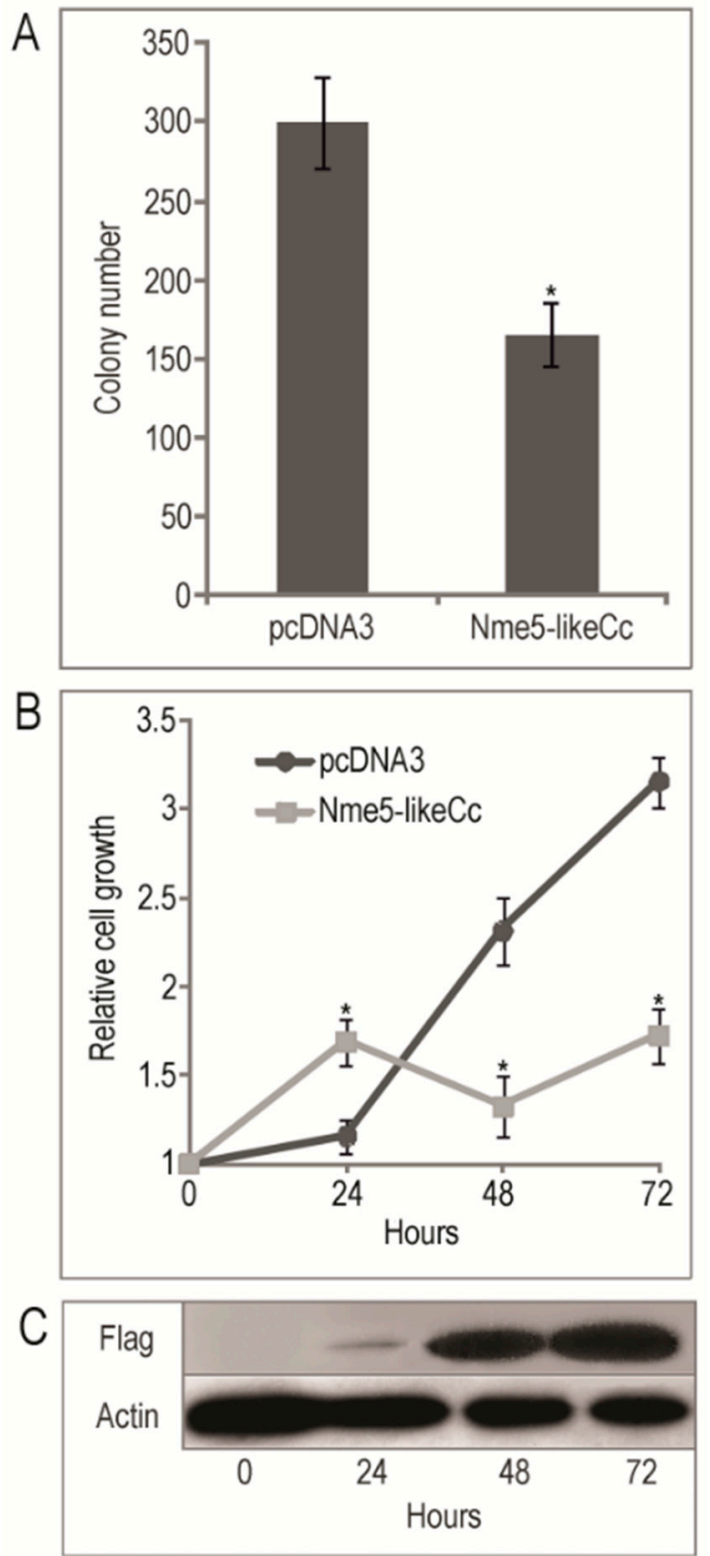

Figure 5. (A) Quantitative results of soft agar colonization assay with HEK293T cells transfected with pcDNA3-Nme5-likeCc or empty vector pcDNA3 (B) The relative growth rates assessed by CellTiter-Glo assay of HEK293T cells transfected with pcDNA3-Nme5-likeCc or empty vector pcDNA3 and protein blot validation of Flag-Nme5-likeCc expression (C). Data are representative of three independent experiments $\left({ }^{*} p<0.05\right)$. 


\section{Discussion}

Distribution analyses indicate that the ancestor of all eukaryotes probably possessed two Group II members of Nme family of proteins, namely Nme5-like and Nme7-like. The domain organization of Nme5-like protein from red algae C. crispus probably reflects the structure of the ancestral protein (Figure 6). Phylogenetic analyses revealed that the C-terminal end of Nme5-likeCc is most similar to recent metazoan AK5 protein. We propose a hypothesis that the ancestral gene split in two genes very early in the eukaryotic evolution but remained conserved in several basal eukaryotic representatives. The human AK5 is cytosolic, or both nuclear and cytosolic [66] expressed almost exclusively in the brain, the pons and the spinal cord. This active kinase phosphorylates AMP, dAMP, CMP, and dCMP using ATP or GTP as phosphate donors [67]. Interestingly, it can also use ATP and GTP to phosphorylate CDP, GDP, UDP, dADP, dCDP, dGDP, and TDP and, like many other adenylate kinases, acts like an NDP kinase [68]. The adenylate kinase complements NDPK function in the $n d k$-disrupted strains of Escherichia coli [69]. The NDP kinase is absent in Ureaplasma parvum genome, but $U$. paroum possesses five nucleoside monophosphate kinases (NMPKs): adenylate kinase (ADK), cytidylate kinase (CMPK), uridylate kinase (UMPK), guanylate kinase (GMPK), and thymidylate kinase (TMPK). ADK, CMPK, UMPK, and TMPK from Ureaplasma were purified and characterized and it was discovered that these NMPKs are base specific and are capable of converting (d)NMPs directly to (d)NTPs [70]. These intriguing connections between ADK and NDPK enzymes can be further elucidated by the analyses of the ancestral Nme5-likeCc protein. Future site-directed mutational studies should explain whether its NDPK activity is due to the active ADK domain and if the NDK domain lost its NDPK activity very early in the evolution of eukaryotes. The crystal structure of this multimeric enzyme should reveal interactions between NDK and ADK domains that are essential for its activity and confirm if these interactions still exist, even after the ancestral gene split (e.g., interactions between human Nme5 and AK5). Our analyses showed that Nme5-likeCc protein can bind to various types of DNA. It can bind to single-stranded telomeric DNA (TTAGGG) 6 , to the double-stranded 57-bp nuclease hypersensitive element of the $c-m y c$ promoter, and also to the single-stranded circular DNA from bacteriophage $\phi X 174$ like human Nme2 [53,59,71]. It is yet to be determined whether this affinity to various types of DNA is sequence specific. Nonspecific DNA binding by Nme5-likeCc is not incompatible with potential sequence-specific DNA-binding because, for example, human transcription factor $\mathrm{Nme} 2$ also binds the DNA sequence nonspecifically, particularly when the substrate DNA is single-stranded [72]. It should also be elucidated if the more pronounced nuclear localization of the EGFP-Nme5-likeCc in HEK293T cells is associated with its potential transcriptional or some other nuclear activity.

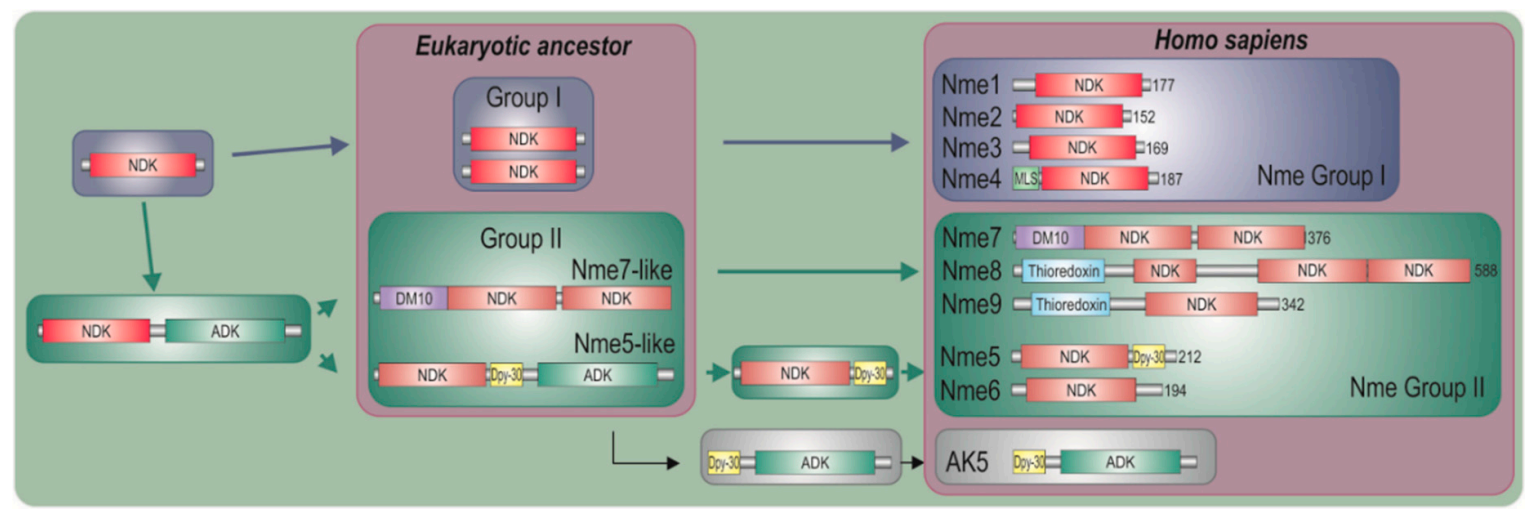

Figure 6. Proposed schematic model for the evolution of recent human Nme Group II enzymes.

Hexameric conformation is required for stability as well as for efficient enzyme catalysis. The site-directed mutagenesis and X-ray structures of Nme enzymes identified nine amino acid residues crucial for quaternary structure, nucleotide binding and catalysis [24]. All of these residues are conserved in Nme5-likeCc (Lys-14, Tyr-52, Phe-60, Arg-88, Thr-94, Arg-108, Asn-118, His-121 and 
Glu-132). In human inactive Nme5, Leu-94 and Asn-100 replace Arg and Thr residues, respectively which are involved in the interaction with the $\beta$-phosphate and the maintenance of the quaternary structure [24]. It was also shown that Ser-120 and Pro-96 in Nme1 protein are important for hexameric oligomerization [73]. The serine (Ser-123) residue is conserved in Nme5-likeCc. The insertion of three amino acids in the Kpn-loop present in the human Nme5 is evident in the ancestral Nme5-likeCc, as well. This insertion is located near Pro-96 (Nme1). Thus, we can conclude that although all the residues necessary for the hexameric structure are present in Nme5-likeCc enzyme, and known residues that could impede this structure are absent, the insertion of three amino acids seems to have an impact on the multimeric structure of Nme5-likeCc. However, the multimeric formation of the Nme enzyme that exceeds conjugation of more than six monomers has not yet been described. Adenylate kinase enzymes can form both dimers and higher supramolecular structures [74,75]. The crystal structure of the adenylate kinase from maize revealed that the enzyme can form rods that are linear assemblies of hexamers. It was proposed that the supramolecular assembly into rods occur in vivo overnight in mesophyll chloroplasts. Presumably rods represent a natural inactive storage form that assembles at night when maize stops $\mathrm{CO}_{2}$ assimilation, i.e., most of the AMP production via $\mathrm{C}_{4}$ cycle [75]. This supramolecular assembly might have originated very early in plant evolution and might also be connected to a $\mathrm{C}_{4}$-like carbon-fixation pathway that might be present in red algae. Most of the essential genes related to the $\mathrm{C}_{4}$-pathway are present in red algae and special $\mathrm{C}_{4}$-like carbon-fixation pathway might play an important role in the conchocelis stage of Rhodophyta [76,77]. It is yet to be determined if the supramolecular assembly of the Nme5-likeCc is characteristic for particular developmental stage during the life cycle of $C$. crispus.

Our results show that besides the role in the maintenance of the cellular NTP pool, Nme5-likeCc probably has an impact on cell proliferation. It was suggested that NF- $\mathrm{KB}$ is a key executor of human Nme5 in regulating apoptosis and the cell cycle. Human Nme 5 was capable of binding NF-kB p65 and affecting its expression level, suggesting that Nme5 probably acted upstream of NF- $\mathrm{KB}$ p65 pathway. However, the overexpression of Nme5-likeCc did not induce apoptosis (data not shown) in HEK293T cells, which may suggest that the mechanism underlying this effect was established later in metazoan evolution. These results support the idea that the algal protein has a different cellular function in comparison to its human homolog. Therefore, we conclude that the structure of the ancestral Nme5 gene has changed during metazoan evolution, possibly in correlation with the function of the protein.

\section{Materials and Methods}

\subsection{Distribution of the Nme Protein Family Across Eukaryotic Supergroups and Phylogenetic Analyses}

Eukaryotic Nme proteins from model organisms with fully sequenced genomes were obtained from the NCBI non-redundant (NR) database (http://blast.ncbi.nlm.nih.gov/Blast.cgi). Additionally, BLASTP on the Ensembl database (http://www.ensembl.org/index.html) were used. Genomes were also searched at the http://www.broadinstitute.org/annotation/genome/multicellularity_project/GenomesIndex.html. Domain architectures of retrieved sequences were obtained from the databases Pfam (http://www. sanger.ac.uk/Software/Pfam) and SMART (http://smart.embl.de/) and examined through the NCBI conserved domain search website (http://www.ncbi.nlm.nih.gov/Structure/cdd/cdd.shtml). The 3D structures of the ADK, Dpy-30, and NDK domains were modeled by homology-modeling using SWISS-MODEL (http://swissmodel.expasy.org//SWISS-MODEL.html) and molecular presentations were generated using the PyMOL program (http://www.pymol.org).

The collected amino acid sequences were aligned with MUSCLE (Multiple Sequence Comparison by Log- Expectation) multiple alignment tool, using default settings [78]. The multiple alignment was subjected to maximum-likelihood (ML) analysis using MEGA6 (Molecular Evolutionary Genetics Analysis) [79], while the Bayesian MCMC analysis was conducted in MrBayes 3.1.2 [80]. The model for the ML analysis was selected with ProtTest 2.4 and the Akaike information criterion (AIC) [81], which indicated a Le_Gascuel model $(\mathrm{I}+\mathrm{G})$ [82]. Bootstrap tests were performed with 1000 replicates. 


\subsection{Isolation of Genomic DNA from Chondrus Crispus and Nme5-Like Gene Cloning}

The genomic DNA from the red alga, C. crispus (Gigartinales, Rhodophyta) was extracted using DNeasy Plant Mini Kit (Qiagen, Hilden, Germany), according to the manufacturer's protocols, with the following modifications: $100 \mathrm{mg}$ of frozen tissue was ground in liquid nitrogen and resuspended in $800 \mu \mathrm{L}$ of lysis buffer. Samples were vigorously vortexed for several minutes and incubated for $30 \mathrm{~min}$ at $65{ }^{\circ} \mathrm{C}$ with shaking. A centrifugation step was added to remove potential clumps. Approximately $5 \mu \mathrm{g}$ of DNA was obtained from $100 \mathrm{mg}$ of tissue powder.

For the overproduction of recombinant Nme5-likeCc protein 5'-CTGCACATATGGTCGGC CTGCAAATCGAG-3' and 5'-ATATGGATCCTTTTAAAAAAGGCCGATCAC-3' set of primers were used to amplify Nme5-likeCc. PCR product and pET-15b expression vector were ligated after $\mathrm{NdeI} /$ BamHI restriction.

For the localization assay, Nme5-likeCc was cloned in fusion with EGFP into pEGFP-C1 (XhoI/BamHI restriction sites) using the following set of primers: $5^{\prime}$-CCCACTCGAGCTATGGTCGGCC TGCAAATCG-3' and 5'-ATATGGATCCTTTTAAAAAAGGCCGATCAC-3' .

For cell proliferation, apoptosis, and soft agar colonization, assay mammalian expression vector pcDNA3 was used to clone Nme5-likeCc into BamHI/EcoRI restriction sites using the following set of primers: 5'-CTAGGGATCCACGAGATGGACTACAAGGACGACGACGATAAGATGGTCGGC CTGCAAATC-3' and 5'-GAATATGAATTCTTTTAAAAAAGGCCGATCAC-3'.

All PCR reactions were performed using Q5 High-Fidelity DNA Polymerase (NEB). Plasmid constructs were verified by sequencing (ABI PRISM 3100-Avant Genetic Analyzer, Applied Biosystems, Foster City, CA, USA) using ABI PRISM BigDye Terminator v.3.1 Ready Reaction Cycle Sequencing Kit (Applied Biosystems, Foster City, CA, USA).

\subsection{Expression and Purification of the Recombinant Nme5-LikeCc Protein and Western Analyses}

The soluble recombinant His-Nme5-likeCc protein, visible after SDS-PAGE, was obtained under the following growth conditions: Escherichia coli strain BL21(DE3) harboring the plasmid was grown to $\mathrm{OD}_{600} 1.2$ and protein expression was induced with $0.05 \mathrm{mM} \mathrm{IPTG}$ for $1 \mathrm{~h}$ at $30{ }^{\circ} \mathrm{C}$. Bacteria were collected by centrifugation, resuspended in lysis buffer $(50 \mathrm{mM}$ Tris $\mathrm{HCl}, 300 \mathrm{mM} \mathrm{NaCl}, 10 \mathrm{mM}$ imidazole, and $1 \mathrm{mg} / \mathrm{mL}$ lysozyme), incubated $30 \mathrm{~min}$ on ice and sonicated $8 \times 30 \mathrm{sec}$ ( $50 \%$ of full power). After $25 \mathrm{~min}$ of centrifugation $(12,000 \mathrm{rpm})$ at $4{ }^{\circ} \mathrm{C}$, the supernatant was applied onto cobalt-charged agarose column (TALON). Histidine tagged proteins was eluted with $300 \mathrm{mM}$ imidazole. Collected eluates were separated by SDS-PAGE (Bio-Rad, Hercules, CA, USA) and electrotransfered onto PVDF Hybond-P membrane (Amersham Biosciences, Buckinghamshire, United Kingdom). For the detection of His-Nme5-likeCc, the membranes were incubated with anti-His antibody (Amersham Biosciences, Buckinghamshire, United Kingdom). Protein bands were visualized using chemiluminescence detection (Amersham ECL Plus, GE Healthcare Chicago, IL, USA). Nme5-likeCc protein was concentrated and desalted using Amicon Ultra 10K device (Millipore, Burlington, MA, USA). The same Ultracel was used for buffer exchange (Nme buffer, [53]).

\subsection{Oligomerization of Protein and Gel Filtration Chromatography}

The oligomerization of the recombinant Nme5-likeCc protein was performed in PBS buffer as follows: $300 \mathrm{ng}$ of protein were pre-incubated in PBS at room temperature and various concentrations of glutaraldehyde were added to initiate the cross-linking. Following 15 min incubation, the reaction was quenched with $0.2 \mathrm{M}$ Tris- $\mathrm{HCl}$, $\mathrm{pH} 7.5$, for $15 \mathrm{~min}$ at room temperature. The reaction product was subjected to $12 \%$ SDS-PAGE, transferred onto PVDF Hybond-P membrane (Amersham Biosciences, Buckinghamshire, United Kingdom) and visualized as described before. Human Nme2 protein was used as a control.

Gel filtration chromatography using the fast protein liquid chromatography (FPLC) system was employed for the determination of the protein MW. Recombinant Nme5-likeCc was loaded onto 
HiLoad 26/600 Superdex 200 prep grade column and eluted with Nme buffer [53] at a flow rate of $1 \mathrm{~mL} / \mathrm{min}$. The standard protein markers for gel filtration chromatography were as follows: ferritin $(440 \mathrm{kDa}), \beta$-amylase $(200 \mathrm{kD})$ and alcohol dehydrogenase $(150 \mathrm{kD})$.

\subsection{NDP Kinase Assay}

NDPK activity was measured using a coupled pyruvate kinase-Lactate dehydrogenase (PK-LDH) assay $[83,84]$ in the presence of various phosphate donors (ATP, dATP, GTP, and dGTP) and dTDP as phosphate acceptors. Reaction mixtures comprised $50 \mathrm{mM}$ Tris- $\mathrm{HCl} \mathrm{pH} \mathrm{7.4,75} \mathrm{mM} \mathrm{KCl,} 5 \mathrm{mM} \mathrm{MgCl}{ }_{2}$, and $1 \mathrm{mM}$ phosphoenolpyruvate, $0.1 \mathrm{mg} / \mathrm{mL}$ NADH, $1 \mathrm{mM}$ (d)NTP, $0.2 \mathrm{mM}$ dTDP, $2 \mathrm{U} / \mathrm{mL}$ of PK (from rabbit muscle, SIGMA, St. Louis, MO, USA), $2.5 \mathrm{U} / \mathrm{mL}$ of LDH (from rabbit muscle, SIGMA, St. Louis, MO, USA) and $1 \mathrm{mg} / \mathrm{mL}$ BSA. Reactions were initiated by the addition of $50 \mathrm{ng}$ of Nme5-likeCc enzyme and the activity was monitored in an Ultrospec 2100 pro (Amersham Pharmacia Biotech, Amersham, Buckinghamshire, United Kingdom) by measuring the decrease in absorbance at $340 \mathrm{~nm}$. All reactions were performed in triplicate. Results are presented as an average of three measurements \pm standard deviations.

\subsection{DNA-Binding Assay}

The affinity of recombinant Nme5-likeCc to various types of DNA was tested in vitro. Reactions contained $10 \mathrm{ng}$ of single-stranded circular DNA from bacteriophage $\varphi$ X174 (NEB) and $10 \mathrm{ng}$ of double-stranded circular DNA (bacteriophage $\varphi$ X174 RF I (NEB)). The amount of purified protein is indicated (Figure 2). BSA was used as a control. The reaction mixture was incubated in $20 \mu \mathrm{L}$ of buffer containing $100 \mathrm{mM} \mathrm{KCl}, 10 \mathrm{mM} \mathrm{MgCl}_{2}, 50 \mathrm{mM}$ Tris $\mathrm{HCl} \mathrm{pH} 7.5,0.2 \mathrm{mM}$ DTT, $10 \mu \mathrm{g} / \mathrm{mL}$ BSA. After $45 \mathrm{~min}$ of incubation at $37{ }^{\circ} \mathrm{C}$, products were subjected to gel electrophoresis in 1\% agarose and stained with SYBR gold (Invitrogen). Thirty nanograms of double-stranded 57-bp nuclease hypersensitive element of the c-myc promoter (5'-GATCCCCAGT СТССТССССАССТТССССАСССТССССАСССТССССАТАAGСGAATT-3'), as well as $30 \mathrm{ng}$ of single-stranded telomeric DNA (TTAGGG) 6 were incubated with recombinant protein in the same reaction buffer. After $30 \mathrm{~min}$ of incubation at $37^{\circ} \mathrm{C}$, products were subjected to gel electrophoresis in $4 \%$ agarose and stained with SYBR gold (Invitrogen, Carlsbad, CA, USA).

\subsection{Transient Transfections and Laser Scanning Confocal Microscopy}

HeLa and HEK293T cells were used for transfection by Lipofectamine 3000 reagent (Invitrogen), according to the manufacturer's instructions. Twenty-four hours prior to transfection, $5 \times 10^{4}$ cells were seeded onto 24-well culture slides containing DMEM supplemented with 10\% FBS and grown until $80 \%$ confluent. Cells were transfected with $500 \mathrm{ng}$ of plasmid DNA. Forty-eight hours post transfection, the cells were washed with PBS pH 7.5, fixed in $4 \%$ formaldehyde, and mounted in SlowFade Diamond Antifade Mountant, with or without DAPI (Molecular Probes, Eugene, OR, USA).

Fluorescent images were obtained using a Leica SP8 X FLIM laser scanning confocal microscope (Leica Microsystems, Wetzlar, Germany) equipped with HC PL APO CS2 63×/1.40 OIL objective. GFP was excited by $488 \mathrm{~nm}$, CFP using $433 \mathrm{~nm}$, and DAPI using $405 \mathrm{~nm}$ laser lines.

\subsection{Soft Agar Colonization Assay}

HEK293T cells were transfected as described above with FLAG-Nme5-likeCc or empty pcDNA3 expression vector in triplicate. Forty-eight hours post-transfection cells were suspended in $1 \mathrm{~mL} \mathrm{10 \%}$ FBS DMEM, containing $0.36 \%$ agar and layered on a $0.75 \%$ agar in a 6 -well plate at a concentration of $5 \times 10^{3}$ cells/well. Cells were incubated for 16 days at $37^{\circ} \mathrm{C}$ and $5 \% \mathrm{CO}_{2}$. Colonies were stained with $0.005 \%$ Crystal Violet and counted. 


\subsection{Cell Proliferation Assay}

Cells were transfected as described above, trypsinized $24 \mathrm{~h}$ post-transfection, and $10^{3}$ viable cells suspended in $90 \mu \mathrm{L} \mathrm{10 \%} \mathrm{FBS} \mathrm{DMEM} \mathrm{were} \mathrm{added} \mathrm{to} \mathrm{each} \mathrm{well} \mathrm{of} \mathrm{96-well} \mathrm{plates.} \mathrm{Cell} \mathrm{proliferation}$ was measured using CellTiter-Glo Luminescent Cell Viability Assay (Promega, Madison, Wisconsin, United States) according to the manufacturer's instructions with luminometer Infinite 200 (TECAN, Männedorf, Switzerland). The concentration of ATP was measured in triplicate, and error bars represent the $95 \%$ confidence interval. The expression of FLAG-Nme5-likeCc was checked by Western blot analyses with anti-FLAG M2 antibody (1:5000) (Sigma-Aldrich, St. Louis, MO, USA).

\subsection{Detection of Apoptosis}

Cells were transfected as described above, trypsinized $24 \mathrm{~h}$ post-transfection, and $5 \times 10^{3}$ viable cells suspended in $100 \mu \mathrm{L} \mathrm{10 \%} \mathrm{FBS} \mathrm{DMEM} \mathrm{were} \mathrm{seeded} \mathrm{in} \mathrm{96-well} \mathrm{culture} \mathrm{plates.} \mathrm{Caspase-3/7} \mathrm{activity}$ was measured using the Caspase-Glo 3/7 Assay Kit (Promega, Madison, Wisconsin, United States) according to the manufacturer's instructions with luminometer Infinite 200 (TECAN, Männedorf, Switzerland).

\subsection{Statistical Analyses}

Statistical analysis was performed using Student's $t$-test. Probabilities of less than 0.05 were considered statistically significant.

Supplementary Materials: The following are available online at http://www.mdpi.com/1660-3397/18/1/13/s1, Figure S1: Crystal structure of human nucleoside diphosphate kinase A S120G complexed with ADP (PDBID: 2HVE1) (orange, A), overlaid with human Nme5 (green, B) or Nme5-likeCc (white, C). Arrows indicate the ADP-binding cavity. Note disturbances produced by 3 aa insertion in Kpn loop in human Nme5 indicated by yellow arrows, Table S1: The percentage of identical amino acids and overall sequence similarity between NDPK domains.

Author Contributions: D.P.: A.M., M.H. and H.Ć. carried out the molecular genetic studies and the sequence analyses. D.P., A.M. and H.Ć. participated in genomic DNA preparation, sequencing and cloning of Nme5. D.P., M.K., M.H.B. carried out colocalization and bioassays. D.P. and H.Ć. conceived and oversaw the project. D.P., M.K., A.M. and H.Ć. drafted the manuscript. A.M., M.H.B., M.H. and H.Ć. reviewed and edited the manuscript. All authors discussed and approved the final manuscript. All authors have read and agreed to the published version of the manuscript.

Funding: This research was funded by the Croatian Ministry of Science, Education and Sports grant 098-0982913-2478 and Croatian Government and the EU through the European Regional Development Fund-The Competitiveness and Cohesion Operational Programme (KK.01.1.1.01), The Scientific Centre of Excellence for Marine Bioprospecting-BioProCro.

Acknowledgments: We thank Ana Smolko (Division of Molecular Biology, Ruđer Bošković Institute, Zagreb, Croatia) for FPLC analysis.

Conflicts of Interest: The authors declare no conflict of interest.

\section{References}

1. Steeg, P.S.; Bevilacqua, G.; Kopper, L.; Thorgeirsson, U.P.; Talmadge, J.E.; Liotta, L.A.; Sobel, M.E. Evidence for a novel gene associated with low tumor metastatic potential. J. Natl. Cancer Inst. 1988, 80, 200-204. [CrossRef] [PubMed]

2. Desvignes, T.; Pontarotti, P.; Fauvel, C.; Bobe, J. Nme protein family evolutionary history, a vertebrate perspective. BMC Evol. Biol. 2009, 9, 256. [CrossRef] [PubMed]

3. Yoon, J.H.; Singh, P.; Lee, D.H.; Qiu, J.; Cai, S.; O'Connor, T.R.; Chen, Y.; Shen, B.; Pfeifer, G.P. Characterization of the $3^{\prime} \rightarrow 5^{\prime}$ exonuclease activity found in human nucleoside diphosphate kinase 1 (NDK1) and several of its homologues. Biochemistry 2005, 44, 15774-15786. [CrossRef] [PubMed]

4. Tsuiki, H.; Nitta, M.; Furuya, A.; Hanai, N.; Fujiwara, T.; Inagaki, M.; Kochi, M.; Ushio, Y.; Saya, H.; Nakamura, H. A Novel Human Nucleoside Diphosphate (NDP) Kinase, Nm23-H6, Localizes in Mitochondria and Affects Cytokinesis. J. Cell. Biochem. 1999, 76, 254-269. [CrossRef] 
5. Herak Bosnar, M.; Radić, M.; Ćetković, H. A young researcher's guide to NME/Nm23/NDP Kinase. Period. Biol. 2018, 120, 3-9. [CrossRef]

6. Postel, E.H. Multiple biochemical activities of Nm23/NDP kinase in gene regulation. J Bioenerg. Biomembr. 2003, 35, 31-40. [CrossRef] [PubMed]

7. Hartsough, M.T.; Morrison, D.K.; Salerno, M.; Palmieri, D.; Ouatas, T.; Mair, M.; Patrick, J.; Steeg, P.S. Nm23-H1 metastasis suppressor phosphorylation of kinase suppressor of Ras via a histidine protein kinase pathway. J. Biol. Chem. 2002, 277, 32389-32399. [CrossRef]

8. Fan, Z.; Beresford, P.J.; Oh, D.Y.; Zhang, D.; Lieberman, J. Tumor suppressor Nm23-H1 is a granzyme A-activated DNase during CTL-mediated apoptosis, and the nucleosome assembly protein SET is its inhibitor. Cell 2003, 112, 659-672. [CrossRef]

9. Lee, M.Y.; Jeong, W.J.; Oh, J.W.; Choi, K.Y. Nm23H2 inhibits EGF- and Ras-induced proliferation of NIH3T3 cells by blocking the ERK pathway. Cancer Lett. 2009, 275, 221-226. [CrossRef]

10. Gervasi, F.; D’Agnano, I.; Vossio, S.; Zupi, G.; Sacchi, A.; Lombardi, D. Nm23 influences proliferation and differentiation of PC12 cells in response to nerve growth factor. Cell Growth Differ. 1996, 7, 1689-1695.

11. Masoudi, N.; Fancsalszky, L.; Pourkarimi, E.; Vellai, T.; Alexa, A.; Reményi, A.; Gartner, A.; Mehta, A.; Takács-Vellai, K. The NM23-H1/H2 homolog NDK-1 is required for full activation of Ras signaling in C. elegans. Development 2013, 140, 3486-3495. [CrossRef] [PubMed]

12. Takacs-Vellai, K.; Vellai, T.; Farkas, Z.; Mehta, A. Nucleoside diphosphate kinases (NDPKs) in animal development. Cell. Mol. Life Sci. 2015, 72, 1447-1462. [CrossRef] [PubMed]

13. Lombardi, D.; Palescandolo, E.; Giordano, A.; Paggi, M.G. Interplay between the antimetastatic Nm23 and the retinoblastoma-related $\mathrm{Rb} 2 / \mathrm{p} 130$ genes in promoting neuronal differentiation of PC12 cells. Cell Death Differ. 2001, 8, 470-476. [CrossRef] [PubMed]

14. Lombardi, D.; Lacombe, M.L.; Paggi, M.G. Nm23: Unraveling its biological function in cell differentiation. J. Cell. Physiol. 2000, 182, 144-149. [CrossRef]

15. Boissan, M.; Dabernat, S.; Peuchant, E.; Schlattner, U.; Lascu, I.; Lacombe, M.L. The mammalian Nm23/NDPK family: From metastasis control to cilia movement. Mol. Cell. Biochem. 2009, 329, 51-62. [CrossRef]

16. Palacios, F.; Schweitzer, J.K.; Boshans, R.L.; D'Souza-Schorey, C. ARF6-GTP recruits Nm23-H1 to facilitate dynamin-mediated endocytosis during adherens junctions disassembly. Nat. Cell Biol. 2002, 4, 929-936. [CrossRef]

17. Boissan, M.; Montagnac, G.; Shen, Q.; Griparic, L.; Guitton, J.; Romao, M.; Sauvonnet, N.; Lagache, T.; Lascu, I.; Raposo, G.; et al. Membrane trafficking. Nucleoside diphosphate kinases fuel dynamin superfamily proteins with GTP for membrane remodeling. Science 2014, 344, 1510-1515. [CrossRef]

18. Marino, N.; Marshall, J.C.; Collins, J.W.; Zhou, M.; Qian, Y.; Veenstra, T.; Steeg, P.S. Nm23-H1 binds to gelsolin and inactivates its actin-severing capacity to promote tumor cell motility and metastasis. Cancer Res. 2013, 73, 5949-5962. [CrossRef]

19. Ignesti, M.; Barraco, M.; Nallamothu, G.; Woolworth, J.A.; Duchi, S.; Gargiulo, G.; Cavaliere, V.; Hsu, T. Notch signaling during development requires the function of awd, the Drosophila homolog of human metastasis suppressor gene Nm23. BMC Biol. 2014, 12, 12. [CrossRef]

20. Thakur, R.K.; Yadav, V.K.; Kumar, A.; Singh, A.; Pal, K.; Hoeppner, L.; Saha, D.; Purohit, G.; Basundra, R.; Kar, A.; et al. Non-metastatic 2 (NME2)-mediated suppression of lung cancer metastasis involves transcriptional regulation of key cell adhesion factor vinculin. Nucleic Acids Res. 2014, 42, 11589-11600. [CrossRef]

21. Moreno, V.; Gonzalo, P.; Gomez-Escudero, J.; Pollan, A.; Acin-Perez, R.; Breckenridge, M.; Yáñez-Mó, M.; Barreiro, O.; Orsenigo, F.; Kadomatsu, K.; et al. An EMMPRIN-gamma-catenin-Nm23 complex drives ATP production and actomyosin contractility at endothelial junctions. J. Cell Sci. 2014, 127, 3768-3781. [CrossRef] [PubMed]

22. Perina, D.; Bosnar, M.H.; Mikoc, A.; Muller, W.E.G.; Cetkovic, H. Characterization of Nme6-like gene/protein from marine sponge Suberites domuncula. Naunyn Schmied. Arch. Pharmacol. 2011, 384, 451-460. [CrossRef]

23. Liu, P.; Choi, Y.K.; Qi, R.Z. NME7 is a functional component of the gamma-tubulin ring complex. Mol. Biol. Cell 2014, 25, 2017-2025. [CrossRef] [PubMed]

24. Munier, A.; Feral, C.; Milon, L.; Pinon, V.P.; Gyapay, G.; Capeau, J.; Guellaen, G.; Lacombe, M.L. A new human Nm23 homologue (Nm23-H5) specifically expressed in testis germinal cells. FEBS Lett. 1998, 434, 289-294. [CrossRef] 
25. Munier, A.; Serres, C.; Kann, M.L.; Boissan, M.; Lesaffre, C.; Capeau, J.; Fouquet, J.P.; Lacombe, M.L. Nm23/NDP kinases in human male germ cells: Role in spermiogenesis and sperm motility? Exp. Cell Res. 2003, 289, 295-306. [CrossRef]

26. Sarkar, H.; Arya, S.; Rai, U.; Majumdar, S.S. A Study of Differential Expression of Testicular Genes in Various Reproductive Phases of Hemidactylus flaviviridis (Wall Lizard) to Derive Their Association with Onset of Spermatogenesis and Its Relevance to Mammals. PLoS ONE 2016, 11, e0151150. [CrossRef] [PubMed]

27. Choi, Y.J.; Cho, S.K.; Hwang, K.C.; Park, C.; Kim, J.H.; Park, S.B.; Hwang, S.; Kim, J.H. Nm23-M5 mediates round and elongated spermatid survival by regulating GPX-5 levels. FEBS Lett. 2009, 583, 1292-1298. [CrossRef] [PubMed]

28. Ostrowski, L.E.; Blackburn, K.; Radde, K.M.; Moyer, M.B.; Schlatzer, D.M.; Moseley, A.; Boucher, R.C. A proteomic analysis of human cilia: Identification of novel components. Mol. Cell. Proteom. 2002, 1, 451-465. [CrossRef]

29. Li, F.; Hu, G.; Jiang, Z.; Guo, J.; Wang, K.; Ouyang, K.; Wen, D.; Zhu, M.; Liang, J.; Qin, X.; et al. Identification of NME5 as a contributor to innate resistance to gemcitabine in pancreatic cancer cells. FEBS J. 2012, 279, 1261-1273. [CrossRef]

30. Li, F.; Jiang, Z.; Wang, K.; Guo, J.; Hu, G.; Sun, L.; Wang, T.; Tang, X.; He, L.; Yao, J..; et al. Transactivation of the human NME5 gene by Sp1 in pancreatic cancer cells. Gene 2012, 503, 200-207. [CrossRef]

31. Goc, A.; Kochuparambil, S.T.; Al-Husein, B.; Al-Azayzih, A.; Mohammad, S.; Somanath, P.R. Simultaneous modulation of the intrinsic and extrinsic pathways by simvastatin in mediating prostate cancer cell apoptosis. BMC Cancer 2012, 12, 409. [CrossRef] [PubMed]

32. Ansoleaga, B.; Jove, M.; Schluter, A.; Garcia-Esparcia, P.; Moreno, J.; Pujol, A.; Pamplona, R.; Portero-Otín, M.; Ferrer, I. Deregulation of purine metabolism in Alzheimer's disease. Neurobiol. Aging 2015, 36, 68-80. [CrossRef] [PubMed]

33. Gopal, R.; Foster, K.W.; Yang, P. The DPY-30 domain and its flanking sequence mediate the assembly and modulation of flagellar radial spoke complexes. Mol. Cell. Biol. 2012, 32, 4012-4024. [CrossRef] [PubMed]

34. Hsu, D.R.; Chuang, P.T.; Meyer, B.J. DPY-30, a nuclear protein essential early in embryogenesis for Caenorhabditis elegans dosage compensation. Development 1995, 121, 3323-3334.

35. Jiang, H.; Shukla, A.; Wang, X.; Chen, W.Y.; Bernstein, B.E.; Roeder, R.G. Role for Dpy-30 in ES cell-fate specification by regulation of H3K4 methylation within bivalent domains. Cell 2011, 144, 513-525. [CrossRef]

36. Mehus, J.G.; Deloukas, P.; Lambeth, D.O. NME6: A new member of the Nm23/nucleoside diphosphate kinase gene family located on human chromosome 3p21.3. Hum. Genet. 1999, 104, 454-459. [CrossRef]

37. Edwards, L.; Gupta, R.; Filipp, F.V. Hypermutation of DPYD Deregulates Pyrimidine Metabolism and Promotes Malignant Progression. Mol. Cancer Res. 2016, 14, 196-206. [CrossRef]

38. Wang, C.H.; Ma, N.; Lin, Y.T.; Wu, C.C.; Hsiao, M.; Lu, F.L.; Yu, C.C.; Chen, S.Y.; Lu, J. A shRNA functional screen reveals Nme6 and Nme7 are crucial for embryonic stem cell renewal. Stem Cells 2012, 30, 2199-2211. [CrossRef]

39. Carter, M.G.; Smagghe, B.J.; Stewart, A.K.; Rapley, J.A.; Lynch, E.; Bernier, K.J.; Keating, K.W.; Hatziioannou, V.M.; Hartman, E.J.; Bamdad, C.C. A Primitive Growth Factor, NME7, Is Sufficient to Induce Stable Naive State Human Pluripotency; Reprogramming in This Novel Growth Factor Confers Superior Differentiation. Stem Cells 2016, 34, 847-859. [CrossRef]

40. Vogel, P.; Read, R.; Hansen, G.M.; Freay, L.C.; Zambrowicz, B.P.; Sands, A.T. Situs inversus in Dpcd/Poll ${ }^{-}$, $\mathrm{Nme}^{-}$and Pkd111- mice. Vet. Pathol. 2010, 47, 120-131. [CrossRef]

41. Ikeda, T. NDP kinase 7 is a conserved microtubule-binding protein preferentially expressed in ciliated cells. Cell Struct. Funct. 2010, 35, 23-30. [CrossRef] [PubMed]

42. Miranda, M.R.; de los Milagros Camara, M.; Bouvier, L.A.; Pereira, C.A. TcNDPK2, a Trypanosoma cruzi microtubule-associated nucleoside diphosphate kinase. Mol. Biochem. Parasitol. 2011, 177, 152-155. [CrossRef] [PubMed]

43. Duriez, B.; Duquesnoy, P.; Escudier, E.; Bridoux, A.M.; Escalier, D.; Rayet, I.; Marcos, E.; Vojtek, A.M.; Bercher, J.F.; Amselem, S. A common variant in combination with a nonsense mutation in a member of the thioredoxin family causes primary ciliary dyskinesia. Proc. Natl. Acad. Sci. USA 2007, 104, 3336-3341. [CrossRef] [PubMed] 
44. Sadek, C.M.; Damdimopoulos, A.E.; Pelto-Huikko, M.; Gustafsson, J.A.; Spyrou, G.; Miranda-Vizuete, A. Sptrx-2, a fusion protein composed of one thioredoxin and three tandemly repeated NDP-kinase domains is expressed in human testis germ cells. Genes Cells 2011, 6, 1077-1090. [CrossRef] [PubMed]

45. Miranda-Vizuete, A.; Tsang, K.; Yu, Y.; Jimenez, A.; Pelto-Huikko, M.; Flickinger, C.J.; Sutovsky, P.; Oko, R. Cloning and developmental analysis of murid spermatid-specific thioredoxin-2 (SPTRX-2), a novel sperm fibrous sheath protein and autoantigen. J. Biol. Chem. 2003, 278, 44874-44885. [CrossRef]

46. Sadek, C.M.; Jimenez, A.; Damdimopoulos, A.E.; Kieselbach, T.; Nord, M.; Gustafsson, J.A.; Spyrou, G.; Davis, E.C.; Oko, R.; van der Hoorn, F.A.; et al. Characterization of human thioredoxin-like 2-A novel microtubule-binding thioredoxin expressed predominantly in the cilia of lung airway epithelium and spermatid manchette and axoneme. J. Biol. Chem. 2003, 278, 13133-13142. [CrossRef]

47. Liu, Y.; Yu, J.T.; Wang, H.F.; Hao, X.K.; Yang, Y.F.; Jiang, T.; Zhu, X.C.; Cao, L.; Zhang, D.Q.; Tan, L. Association between NME8 locus polymorphism and cognitive decline, cerebrospinal fluid and neuroimaging biomarkers in Alzheimer's disease. PLoS ONE 2014, 9, e114777. [CrossRef]

48. Chan, G.; White, C.C.; Winn, P.A.; Cimpean, M.; Replogle, J.M.; Glick, L.R.; Cuerdon, N.E.; Ryan, K.J.; Johnson, K.A.; Schneider, J.A.; et al. CD33 modulates TREM2: Convergence of Alzheimer loci. Nat. Neurosci. 2015, 18, 1556-1558. [CrossRef]

49. Yoon, H.S.; Hackett, J.D.; Ciniglia, C.; Pinto, G.; Bhattacharya, D. A molecular timeline for the origin of photosynthetic eukaryotes. Mol. Biol. Evol. 2004, 21, 809-818. [CrossRef]

50. Butterfield, N.J. Bangiomorpha pubescens n. gen., n. sp.: Implications for the evolution of sex, multicellularity, and the Mesoproterozoic/Neoproterozoic radiation of eukaryotes. Paleobiology 2000, 26, 386-404. [CrossRef]

51. Collen, J.; Porcel, B.; Carre, W.; Ball, S.G.; Chaparro, C.; Tonon, T.; Barbeyron, T.; Michel, G.; Noel, B.; Valentin, K.; et al. Genome structure and metabolic features in the red seaweed Chondrus crispus shed light on evolution of the Archaeplastida. Proc. Natl. Acad. Sci. USA 2013, 110, 5247-5252. [CrossRef] [PubMed]

52. Milon, L.; Meyer, P.; Chiadmi, M.; Munier, A.; Johansson, M.; Karlsson, A.; Lascu, I.; Capeau, J.; Janin, J.; Lacombe, M.L. The human Nm23-H4 gene product is a mitochondrial nucleoside diphosphate kinase. J. Biol. Chem. 2000, 275, 14264-14272. [CrossRef] [PubMed]

53. Perina, D.; Bosnar, M.H.; Bago, R.; Mikoc, A.; Harcet, M.; Deželjin, M.; Ćetkovć, H. Sponge non-metastatic Group I Nme gene/protein-Structure and function is conserved from sponges to humans. BMC Evol. Biol. 2011, 11, 87. [CrossRef] [PubMed]

54. Bilitou, A.; Watson, J.; Gartner, A.; Ohnuma, S.I. The Nm23 family in development. Mol. Cell. Biochem. 2009, 329, 17-33. [CrossRef]

55. Desvignes, T.; Pontarotti, P.; Bobe, J. Nme Gene Family Evolutionary History Reveals Pre-Metazoan Origins and High Conservation between Humans and the Sea Anemone, Nematostella vectensis. PLoS ONE 2010, 5, e15506. [CrossRef]

56. Lascu, I.; Chaffotte, A.; Limbourg-Bouchon, B.; Veron, M. A Pro/Ser substitution in nucleoside diphosphate kinase of Drosophila melanogaster (mutation killer of prune) affects stability but not catalytic efficiency of the enzyme. J. Biol. Chem. 1992, 267, 12775-12781.

57. Postel, E.H.; Weiss, V.H.; Beneken, J.; Kirtane, A. Mutational analysis of Nm23-H2/NDP kinase identifies the structural domains critical to recognition of a c-myc regulatory element. Proc. Natl. Acad. Sci. USA 1996, 93, 6892-6897. [CrossRef]

58. Johansson, M.; Mackenzie-Hose, A.; Andersson, I.; Knorpp, C. Structure and mutational analysis of a plant mitochondrial nucleoside diphosphate kinase. Identification of residues involved in serine phosphorylation and oligomerization. Plant Physiol. 2004, 136, 3034-3042. [CrossRef]

59. Postel, E.H. Cleavage of DNA by human Nm23-H2/nucleoside diphosphate kinase involves formation of a covalent protein-DNA complex. J. Biol. Chem. 1999, 274, 22821-22829. [CrossRef]

60. Negroni, A.; Venturelli, D.; Tanno, B.; Amendola, R.; Ransac, S.; Cesi, V.; Calabretta, B.; Raschellà, G. Neuroblastoma specific effects of DR-Nm23 and its mutant forms on differentiation and apoptosis. Cell Death Differ. 2000, 7, 843-850. [CrossRef]

61. McDermott, W.G.; Boissan, M.; Lacombe, M.L.; Steeg, P.S.; Horak, C.E. Nm23-H1 homologs suppress tumor cell motility and anchorage independent growth. Clin. Exp. Metastasis 2008, 25, 131-138. [CrossRef] [PubMed]

62. Dai, Z.; Xiao, W.; Jin, Y. Inhibition of Nm23-H1 gene expression in chronic myelogenous leukemia cells. Oncol. Lett. 2013, 6, 1093-1097. [CrossRef] [PubMed] 
63. Amendola, R.; Martinez, R.; Negroni, A.; Venturelli, D.; Tanno, B.; Calabretta, B.; Raschellà, G. DR-Nm23 expression affects neuroblastoma cell differentiation, integrin expression, and adhesion characteristics. Med. Pediatr. Oncol. 2001, 36, 93-96. [CrossRef]

64. Lee, M.J.; Xu, D.Y.; Li, H.; Yu, G.R.; Leem, S.H.; Chu, I.S.; Kim, I.H.; Kim, D.G. Pro-oncogenic potential of Nm23-H2 in hepatocellular carcinoma. Exp. Mol. Med. 2012, 44, 214-224. [CrossRef] [PubMed]

65. Almgren, M.A.; Henriksson, K.C.; Fujimoto, J.; Chang, C.L. Nucleoside diphosphate kinase A/Nm23-H1 promotes metastasis of NB69-derived human neuroblastoma. Mol. Cancer Res. 2004, 2, 387-394.

66. Panayiotou, C.; Solaroli, N.; Karlsson, A. The many isoforms of human adenylate kinases. Int. J. Biochem. Cell Biol. 2014, 49, 75-83. [CrossRef]

67. Van Rompay, A.R.; Johansson, M.; Karlsson, A. Identification of a novel human adenylate kinase. cDNA cloning, expression analysis, chromosome localization and characterization of the recombinant protein. Eur. J. Biochem. 1999, 261, 509-517. [CrossRef]

68. Amiri, M.; Conserva, F.; Panayiotou, C.; Karlsson, A.; Solaroli, N. The human adenylate kinase 9 is a nucleoside mono- and diphosphate kinase. Int. J. Biochem. Cell Biol. 2013, 45, 925-931. [CrossRef]

69. Lu, Q.; Inouye, M. Adenylate kinase complements nucleoside diphosphate kinase deficiency in nucleotide metabolism. Proc. Natl. Acad. Sci. USA 1996, 93, 5720-5725. [CrossRef]

70. Wang, L. The role of Ureaplasma nucleoside monophosphate kinases in the synthesis of nucleoside triphosphates. FEBS J. 2007, 274, 1983-1990. [CrossRef]

71. Nosaka, K.; Kawahara, M.; Masuda, M.; Satomi, Y.; Nishino, H. Association of nucleoside diphosphate kinase Nm23-H2 with human telomeres. Biochem. Biophys. Res. Commun. 1998, 243, 342-348. [CrossRef] [PubMed]

72. Postel, E.H.; Berberich, S.J.; Rooney, J.W.; Kaetzel, D.M. Human Nm23/nucleoside diphosphate kinase regulates gene expression through DNA binding to nuclease-hypersensitive transcriptional elements. $J$. Bioenerg. Biomembr. 2000, 32, 277-284. [CrossRef] [PubMed]

73. Kim, Y.I.; Park, S.; Jeoung, D.I.; Lee, H. Point mutations affecting the oligomeric structure of Nm23-H1 abrogates its inhibitory activity on colonization and invasion of prostate cancer cells. Biochem. Biophys. Res. Commun. 2003, 307, 281-289. [CrossRef]

74. Dzeja, P.; Terzic, A. Adenylate kinase and AMP signaling networks: Metabolic monitoring, signal communication and body energy sensing. Int. J. Mol. Sci. 2009, 10, 1729-1772. [CrossRef]

75. Wild, K.; Grafmuller, R.; Wagner, E.; Schulz, G.E. Structure, catalysis and supramolecular assembly of adenylate kinase from maize. Eur. J. Biochem. 1997, 250, 326-331. [CrossRef]

76. Chi, S.; Wu, S.; Yu, J.; Wang, X.; Tang, X.; Liu, T. Phylogeny of C4-photosynthesis enzymes based on algal transcriptomic and genomic data supports an archaeal/proteobacterial origin and multiple duplication for most C4-related genes. PLoS ONE 2014, 9, e110154. [CrossRef]

77. Xie, C.; Li, B.; Xu, Y.; Ji, D.; Chen, C. Characterization of the global transcriptome for Pyropia haitanensis (Bangiales, Rhodophyta) and development of cSSR markers. BMC Genom. 2013, 14, 107. [CrossRef]

78. Edgar, R.C. MUSCLE: Multiple sequence alignment with high accuracy and high throughput. Nucleic Acids Res. 2004, 32, 1792-1797. [CrossRef]

79. Tamura, K.; Stecher, G.; Peterson, D.; Filipski, A.; Kumar, S. MEGA6: Molecular Evolutionary Genetics Analysis version 6.0. Mol. Biol. Evol. 2013, 30, 2725-2729. [CrossRef]

80. Ronquist, F.; Huelsenbeck, J.P. MrBayes 3: Bayesian phylogenetic inference under mixed models. Bioinformatics 2003, 19, 1572-1574. [CrossRef]

81. Abascal, F.; Zardoya, R.; Posada, D. ProtTest: Selection of best-fit models of protein evolution. Bioinformatics 2005, 21, 2104-2105. [CrossRef] [PubMed]

82. Le, S.Q.; Gascuel, O. An improved general amino acid replacement matrix. Mol. Biol. Evol. 2008, 25, 1307-1320. [CrossRef] [PubMed]

83. Agarwal, R.P.; Robison, B.; Parks, R.E., Jr. Nucleoside diphosphokinase from human erythrocytes. Methods Enzymol. 1978, 51, 376-386. [PubMed]

84. Postel, E.H.; Ferrone, C.A. Nucleoside diphosphate kinase enzyme activity of Nm23-H2/PuF is not required for its DNA binding and in vitro transcriptional functions. J. Biol. Chem. 1994, 269, 8627-8630.

(C) 2019 by the authors. Licensee MDPI, Basel, Switzerland. This article is an open access article distributed under the terms and conditions of the Creative Commons Attribution (CC BY) license (http://creativecommons.org/licenses/by/4.0/). 